\title{
ACUMULACIÓN DE CONOCIMIENTO, INNOVACIÓN Y COMPETITIVIDAD EN AGLOMERACIONES EMPRESARIALES*
}

\author{
MARÍA EUGENIA MORALES RUBIANO** - SONIA ESPERANZA SANABRIA AGUIRRE*** \\ \& MAYRA ALEJANDRA ARIAS CANTE \\ UNIVERSIDAD MILITAR NUEVA GRANADA
}

Recibido/ Received/ Recebido: 24/02/2010 - Aceptado/ Accepted/Aprovado: 02/09/2010

\begin{abstract}
Resumen
Este documento es producto de una investigación realizada en la industria del cuero, calzado y afines en Bogotá D.C, y busca describir las dinámicas de acumulación de conocimiento, innovación y competitividad en la concentración empresarial ubicada en el Barrio Restrepo. A partir de la revisión de literatura que da cuenta de estudios realizados tanto en países de la región como en algunos países desarrollados, de la información obtenida en entrevistas realizadas a los representantes de las asociaciones de la aglomeración y de la aplicación de encuestas a un grupo de empresarios pertenecientes a la misma, se encontró que contrario a lo que tradicionalmente se cree, ésta no ostenta la calidad de cluster maduro, dado que existen diferentes factores que inciden en la eficiencia colectiva y que afectan las dinámicas de acumulación de conocimiento, innovación y competitividad de la concentración de empresas. Dichos factores están asociados especialmente a la cultura de los empresarios, a las características propias de la actividad económica y a condiciones políticas, sociales, económicas e institucionales del entorno.
\end{abstract}

Palabras clave: Cluster, competitividad, transferencia de conocimiento, innovación.

\section{KNOWLEDGE ACCUMULATION, INNOVATION AND COMPETITIVENESS IN ENTERPRISE AGGLOMERATIONS}

\begin{abstract}
This paper presents the results of the research made in the leather and footwear industry in Bogotá, describing knowledge accumulation, innovation and competitiveness dynamics in enterprise concentration located at Restrepo neighborhood. The literature review of regional countries and developed countries showed how the information obtained in interviews to agglomeration association representatives and surveys made to a group of entrepreneurs, findings suggest that
\end{abstract}

Artículo de investigación resultado del proyecto: Acumulación de conocimiento, innovación y competitividad en una aglomeración empresarial ubicada en Bogotá D.C. Financiado por la Universidad Militar Nueva Granada. Las autoras agradecen a la Doctora Yormary Huertas Directora Ejecutiva de la Asociación Nacional del Sector del Calzado, el Cuero y Afines (ANSECALZ \& AFINES), al Doctor Álvaro Rojas Director Ejecutivo del Centro Tecnológico para la Industria del Calzado, Cuero y Afines (CEINNOVA), a la Doctora María del Pilar Reverón Directora de la Asociación Colombiana de Industriales del Calzado, el Cuero y sus Manufacturas (ACICAM) Seccional Bogotá y Cundinamarca, al Doctor Raúl Páez Director de estudios sectoriales y negociaciones de ACICAM y a los empresarios que participaron en el proceso de recolección de datos, por su valiosa colaboración.

* Administradora de Empresas, Magíster en Administración, Universidad Nacional de Colombia. Docente Investigadora de la Facultad de Ciencias Económicas de la Universidad Militar Nueva Granada, miembro del Grupo de Investigación GECEI. Correo electrónico: maria.morales@unimilitar.edu.co

*** Contadora Pública de la Universidad Nacional, Estudiante de Maestría en Administración de la Universidad Nacional de Colombia, miembro del Grupo de Investigación GECEI. Correo electrónico: sesanabriaa@unal.edu.co

Administradora de Empresas, Universidad Nacional de Colombia. Joven Investigadora del Grupo de Investigación GECEI de la Universidad Militar Nueva Granada. Correo electrónico: alejandra.ariasc@gmail.com 
contrary to traditional beliefs, agglomerations do not have the quality of being a mature cluster. This is explained because there are different factors that influence collective efficiency and affect knowledge accumulation, innovation and competitiveness dynamics of concentration of the studied companies. Such factors are associated especially to entrepreneur culture, economic activity characteristics and political, social, economic and institutional conditions of the environment.

Key words: Cluster, competitiveness, knowledge transference, innovation

\title{
ACUMULAÇÃO DE CONHECIMENTO, INOVAÇÃO E COMPETITIVIDA DE EM CLUSTERS EMPRESARIAIS
}

\begin{abstract}
Resumo
Nesteartigo apresentam-seosresultados da pesquisarealizadanaindústriadocouro, calçadoeafins, em Bogotá D.C., que procurou descrever a dinâmica de acumulação de conhecimento, inovação e competitividade de um cluster localizado no Bairro Restrepo. A revisão de literatura sobre estudos em países da região e em países desenvolvidos, a informação obtida em entrevistas com representantes de associações do cluster e da aplicação de inquéritos a empregadores pertencentes a ele, verificou-se que contudo a crença tradicional - ele não é um cluster maduro. Isto é explicado pelos fatores que afetam a eficiência coletiva e a dinâmica de acúmulo de conhecimento, inovação e competitividade da concentração das empresas estudadas. Estes fatores se associam principalmente à cultura dos empresários, às características da atividade econômica e às condições políticas, sociais, econômicas e institucionais do ambiente.
\end{abstract}

Palavras chave: Cluster, competitividade, transferência de conhecimento, inovação.

Morales, M., Sanabria, S., Arias, M. (2010) Acumulación de conocimiento, innovación y competitividad en aglomeraciones empresariales. En: Revista de la Facultad de Ciencias Económicas de la Universidad Militar Nueva Granada. rev.fac.cienc.econ, XVIII (2)

JEL: L67, M10, O31, R12.

\section{Introducción}

Si bien el interés por el estudio y la comprensión de las aglomeraciones empresariales no es asunto reciente, hoy por hoy ha adquirido mayor relevancia dado que el fortalecimiento de estas estructuras se ha convertido en una estrategia clave para la generación de ventajas competitivas. Lo anterior debido a que en el actual contexto de globalización es el entorno nacional y local en el cual se crean, desarrollan y actúan las empresas el que permite a las mismas la generación de capacidades y habilidades que le otorgarán una posición privilegiada en el ambiente competitivo.

En este sentido, las aglomeraciones se han convertido en terrenos fértiles para la gestación de procesos de cooperación en $360^{\circ 1}$, generando eficiencia colectiva tanto pasiva como activa, alentando el aprovechamiento de beneficios asociados al derramamiento de conocimiento así como de ventajas relacionadas con acciones deliberadas para la

1 Ésta es definida por las autoras como cooperación con todos los agentes que de alguna manera influyen en el desempeño de la aglomeración independientemente del nivel en que se encuentren. La cooperación en $360^{\circ}$ involucra cooperación al interior de las organizaciones que conforman la aglomeración, entre las empresas en los diferentes eslabones de la cadena de valor y con entidades en el nivel meso y macro, dentro de las que cabe destacarse asociaciones, universidades, centros de desarrollo tecnológico y el gobierno en sus diferentes niveles, entre otras. 
solución de problemas conjuntos, realización de actividades de investigación y desarrollo, y marketing, entre otras. En consecuencia, las aglomeraciones se consideran importantes entramados empresariales en los cuales fluye de manera más rápida el conocimiento, favoreciendo procesos de acumulación de conocimiento y desarrollo de innovaciones, factores considerados clave en la competitividad del actual contexto económico.

Es importante aclarar que las concentraciones empresariales pueden exhibir diferentes grados de desarrollo y que los cluster son una categoría a la cual muchas buscan llegar. En este sentido, al igual que en países industrializados, en países en desarrollo se pueden encontrar numerosas aglomeraciones empresariales tanto manufactureras como de servicios, sin embargo, a pesar de los esfuerzos realizados desde los niveles público y privado dichas aglomeraciones no ostentan la calidad de clusters maduros, dado que no exhiben las características dinámicas e innovadoras que se atribuyen a los clusters localizados en países industrializados.

El presente documento tiene como objetivo describir las dinámicas de acumulación de conocimiento, innovación y competitividad en la aglomeración de la industria del cuero, calzado y afines del Barrio Restrepo en Bogotá D.C; para ello el documento se divide en diferentes apartados, en los que se trata en primer lugar, una revisión conceptual sobre aglomeraciones industriales tipo clusters; a continuación se exponen las características básicas de los procesos de generación, acumulación y transferencia de conocimiento en dichas aglomeraciones; se sigue con los factores de competitividad en aglomeraciones empresariales; posteriormente se muestra el diseño metodológico de la investigación; después se exponen los resultados del estudio y, finalmente, se presentan las conclusiones y recomendaciones.

\section{Una aproximación conceptual a las aglomeraciones industriales tipo clusters}

El fenómeno de la concentración espacial, desde el alcance industrial de la actividad económica, ha sido abordado principalmente desde dos perspectivas. Por un lado hay quienes se han orientado al estudio y la comprensión de las aglomeraciones empresariales dedicadas a una misma actividad, denominadas comúnmente economías de localización y por otro, quienes se han centrado en la determinación de las causas por las cuales surgen las ciudades, a partir del estudio de la concentración espacial en todas las actividades económicas, también conocidas como economías de urbanización (Becerra \& Naranjo, 2008; Rosenthal \& Strange, 2004). De tal división, este apartado se enfocará en las primeras, puesto que el caso de estudio que soporta este documento hace referencia a economías de localización.

Al respecto, cabe mencionar que las economías de localización han sido estudiadas desde siglos atrás, encontrándose que los primeros rastros en la literatura económica datan de 1890, año en que Alfred Marshall, economista neoclásico, publicó su libro "Principios de economía". A lo largo de la historia han sido innumerables los aportes a este respecto, dando lugar a la inserción de distintos términos para hacer referencia a estas formas de integración. Dentro de estos términos se tienen: industrias localizadas y distritos industriales (Marshall, 1890), centros de producción (Hoover, 1943), concentraciones (Krugman, 1953), clusters (Porter, 1991), redes industriales, sistemas industriales, sistemas tecnológicos, y áreas de recursos (Almquist, Norgren \& Strandell, 1998, citados en Vera \& Ganga, 2007), entre otros.

De los vocablos antes mencionados, el más difundido en el actual contexto es el de "cluster". Esta forma de integración, ha llegado a permear tanto el ámbito académico como político y económico, dada su relación con las dinámicas de generación, acumulación, transferencia de conocimiento $e$ innovación que permiten a las empresas generar ventajas competitivas y que se generan a partir de la proximidad y el inter-relacionamiento de las empresas a lo largo de la cadena de valor y fuera de ella, incluyendo eslabones posteriores y entidades conexas y de apoyo (Porter, 1991, 2003).

Porter (2003), a quien se aduce introdujo el término en la literatura económica, define cluster como un grupo geográficamente denso de empresas $e$ instituciones conexas, pertenecientes a un campo concreto, unidas por rasgos comunes y comple- 
mentarias entre sí, en los cuales se suele encontrar empresas pertenecientes a los diferentes eslabones de la cadena productiva, así como eslabones posteriores, donde las empresas compiten pero también cooperan. Es importante resaltar que tal definición no dista mucho de las aportadas por otros autores que lo antecedieron, sin embargo, ha sido a partir del trabajo del mencionado autor, que se ha dado un crecimiento representativo en el número de publicaciones y estudios que hacen alusión a este fenómeno, provenientes desde distintas ramas del conocimiento relacionadas con las ciencias sociales (Maskell \& Kebir, 2005).

Otro suceso que muestra la importancia de estas estructuras y el impacto de los planteamientos de Porter (1991; 2003) en el actual contexto, es su destacado rol en los planes de desarrollo económico tanto nacionales como regionales en diferentes países alrededor del mundo, convirtiéndose en un modelo para impulsar el crecimiento y la productividad de las firmas y los territorios. Lo anterior se traduce en la propagación de diferentes políticas como las iniciativas clusters ${ }^{2}$ (Solvell, Lindquist \& Ketels, 2003) y la creación y formalización de instituciones y organizaciones públicas y privadas cuyo propósito es velar porque estas políticas se desarrollen. En Colombia por ejemplo, el fortalecimiento de sectores o clusters de clase mundial hace parte de los cinco pilares de la política nacional de competitividad y productividad desarrollada por el CONPES - Consejo Nacional de Política Económica y Social - con el fin de alcanzar la visión $2032^{3}$ definida por el Gobierno Nacional (CONPES 3527, 2008).

\subsection{Fuentes de aglomeración}

Una fuente es definida como el principio, fundamento $\mathrm{u}$ origen de algo (Diccionario de la Real Academia Española, 2010), así en este apartado se hará referencia a las causas principales que han dado origen al surgimiento de las aglomeraciones empresariales a lo largo de la historia. Éstas pueden ser diferentes para cada caso particular y en algunas ocasiones puede que la aparición de las mismas haya obedecido a una situación incidental y no a una acción deliberada (Schmitz \& Nadvi, 1999, citado en Vera y Ganga, 2007), esto es, hayan surgido de manera espontánea como resultado del asentamiento de una empresa en una localización determinada, alrededor de la cual, posteriormente se asentaron otras firmas (Krugman, 1992, citado en Vera y Ganga, 2007).

Retomando a Marshall (1890), quien como se mencionó antes es el primero en abordar el tema desde la literatura económica, se encuentra que dicho autor identificó como fuentes de aglomeración las condiciones físicas, la disponibilidad de materias primas, la facilidad de acceso al lugar y el patronato de una corte. Aún cuando ha transcurrido más de un siglo de la publicación de su obra, estos factores todavía pueden reconocerse hoy como fuentes de aglomeración, aunque algunos hayan perdido importancia debido a cambios suscitados en el entorno. Así por ejemplo las condiciones físicas continúan determinando la ubicación de actividades como la agricultura y la ubicación de materias primas de actividades como la minería. Sin embargo, la globalización de los mercados y la sofisticación de los medios de comunicación y transporte, han hecho que la ubicación de materias haya perdido relevancia para la mayoría de las actividades industriales, dado que las empresas ahora pueden acceder a materias primas provenientes de cualquier parte del mundo.

En términos de Altenburg (2001), la globalización de los mercados facilita la relocalización de los factores clásicos de producción - capital, materias primas, mano de obra - lo cual no hace necesariamente desaparecer los patrones tradicionales de especialización, pero si hace que estos sean insuficientes

2 Las iniciativas cluster son esfuerzos organizados para incrementar el crecimiento y la competitividad de los clusters dentro de una región, involucrando las agrupaciones empresariales, el gobierno y la comunidad investigadora (Solvell, Lindqvist \& Ketels, 2003).

3 "En 2032 Colombia será uno de los tres países más competitivos de América Latina y tendrá un elevado nivel de ingreso por persona, equivalente al de un país de ingresos medios altos, a través de una economía exportadora de bienes y servicios de alto valor agregado e innovación, con un ambiente de negocios que incentive la inversión local y extranjera, propicie la convergencia regional, mejore las oportunidades de empleo formal, eleve la calidad de vida y reduzca sustancialmente los niveles de pobreza" (CONPES 3527, 2008, p.6). 
para generar ventajas competitivas, adquiriendo mayor relevancia factores como el conocimiento y la innovación.

Krugman (1953) por su parte señala que las aglomeraciones son el resultado de las decisiones de ubicación de las firmas individuales, las cuales están influenciadas por la localización de otras organizaciones, dado que éstas requieren un buen acceso a los mercados y a los artículos que otras empresas fabrican y que son insumos de su propio producto. Estas decisiones de localización fueron plasmadas en un modelo al que el autor denominó modelo de centro, según el cual existen unas fuerzas centrípetas que favorecen la concentración y unas centrífugas que incentivan la desconcentración. Las fuerzas centrípetas son aquellas por las cuales las empresas se proporcionan mercados entre sí, y las fuerzas centrífugas corresponden a la competencia que se genera entre ellas al localizarse cerca; estas dos fuerzas dan lugar a aglomeraciones múltiples.

Trayendo de nuevo a colación la afirmación de Altenburg (2001) según la cual el conocimiento y la innovación han adquirido en el actual contexto mayor relevancia como factores determinantes de la competitividad, se puede destacar que de la misma manera se han convertido en fuentes importantes de aglomeración. En este sentido, Malmberg, Solvell \& Zander (1996), plantean que los flujos entre las empresas hoy no constan solamente de recursos físicos, sino que también hay un intercambio intenso de información de negocios, know how y experiencia tecnológica. Así mismo, sostienen que este proceso de intercambio es más rápido y eficiente cuando las empresas se encuentran agrupadas geográficamente lo cual queda también evidenciado en los aportes de Audretsch \& Feldman, (1996) quienes argumentan que si la habilidad para recibir conocimiento es influenciada por la distancia de la fuente de conocimiento, entonces, la concentración geográfica favorece la transmisión del mismo.

\subsection{Tipos de cluster}

Los clusters pueden ser clasificados de manera general atendiendo a diferentes criterios, entre estos el tipo de productos, el tamaño de las empresas que lo constituyen, la homogeneidad de las industrias, el estado de desarrollo, la dimensión geográfica y el origen de la decisión que dio lugar a su surgimiento (ver Tabla No. 1).

Tabla 1. Tipos de cluster ${ }^{4}$

\begin{tabular}{|c|c|}
\hline \multicolumn{2}{|r|}{ CLASIFICACIÓN } \\
\hline $\begin{array}{l}\text { Según el tipo de bienes o } \\
\text { servicios }\end{array}$ & $\begin{array}{l}\text { Concentran las actividades desarrolladas en ellos, entre otros se pueden encontrar, clusters en la } \\
\text { industria de automóviles, servicios financieros, software y cuero como en el caso de estudio que se } \\
\text { expone en este documento (Ketels, 2003). }\end{array}$ \\
\hline $\begin{array}{l}\text { Según el tamaño de las } \\
\text { empresas }\end{array}$ & $\begin{array}{l}\text { Clusters constituidos por empresas en diferentes fases y modos de producción (Parto, 2008). } \\
\text { Clusters de pequeñas empresas como es el caso de algunos hallados en Italia y América Latina (Al- } \\
\text { tenburg, 2001). }\end{array}$ \\
\hline $\begin{array}{l}\text { Según la homogeneidad } \\
\text { de las industrias }\end{array}$ & $\begin{array}{l}\text { Clusters de empresas aglomeradas alrededor de una actividad relacionada (Marshall, 1890; Arrow, } \\
1962 \text { y Romer, 1986, citados en Maldonado, 2004). } \\
\text { Clusters de empresas pertenecientes a diferentes sectores (Jacobs, 1969, citado en Maldonado, 2004). }\end{array}$ \\
\hline $\begin{array}{l}\text { Según el estado de } \\
\text { desarrollo }\end{array}$ & $\begin{array}{l}\text { Según Vega (2007) los cluster pueden ser: } \\
\text { Embrionarios o en etapa de formación } \\
\text { Consolidados o maduros } \\
\text { Declinación } \\
\text { El grado de madurez está directamente asociado con el establecimiento de redes de cooperación que } \\
\text { dan lugar a dinámicas de generación y difusión de conocimiento e innovación. }\end{array}$ \\
\hline
\end{tabular}

\footnotetext{
4 Elaboración propia.
} 


\section{CLASIFICACIÓN}

\begin{tabular}{|l|l|}
\hline \multirow{3}{*}{$\begin{array}{l}\text { Según su dimensión } \\
\text { geográfica }\end{array}$} & $\begin{array}{l}\text { De acuerdo con Porter (2003) los cluster se pueden clasificar en: } \\
\text { Urbanos }\end{array}$ \\
\hline & $\begin{array}{l}\text { Regionales } \\
\text { Nacionales }\end{array}$ \\
\hline Supranacionales
\end{tabular}

Cabe mencionarse que Altenburg (2001) planteó una clasificación particular para los clusters encontrados en América Latina los cuales agrupó en cinco categorías: (1) Cluster de micro y pequeñas empresas "sobrevivientes", (2) Clusters medianamente diversificados de empresas productoras de bienes de consumo, (3) Clusters basados en el procesamiento de recursos naturales, (4) Clusters de empresas de servicios intensivos en conocimientos, y (5) Clusters dominados por empresas transnacionales. A continuación se hará una breve descripción de cada una de ellas:

Clusters de micro y pequeñas empresas "sobrevivientes": este tipo de clusters está caracterizado por tener escasas barreras a la entrada tanto en conocimientos como en capital, dado que conciernen principalmente a sectores de bajo contenido tecnológico y que requieren baja inversión. Típicamente se encuentran ubicados en zonas pobres con altos niveles de desempleo en donde la creación de nuevas empresas no obedece a las dinámicas económicas sino que hace parte de las estrategias utilizadas por los individuos para encontrar una actividad en que emplearse. Los productos son de baja calidad y presentan bajos niveles de diferenciación y complementariedad, lo cual incide en sus bajos precios. Toda la producción está dirigida al mercado local generando una sobreoferta que limita la disposición de los empresarios para cooperar, lo cual es acentuado aún más, por un ambiente de competencia basado en la imitación del competidor y factores como inestabilidad social, volatilidad de las empresas y falta de mecanismos legales para hacer valer contratos, debido en parte a que muchas de estas empresas operan en la informalidad. La mayoría de los empresarios tiene baja formación académica, los empleados son formados en las mismas empresas y este constituye el principal mecanismo para la transferencia de conocimiento en este tipo de clusters.

Clusters medianamente diversificados de empresas productoras de bienes de consumo: este tipo de clusters está constituido por empresas de diferentes tamaños, desde micro hasta grandes empresas con altos niveles de eficiencia técnica y gerencial, las cuales producen a escalas mayores que las empresas "sobrevivientes" y utilizan bienes de capital más modernos. La mayoría de éstos se ha especializado en bienes de consumo masivo, en algunas ocasiones los mismos que en el tipo de clusters examinado anteriormente, pero también en otros productos que requieren un grado de tecnificación más alto. Su producción está orientada principalmente al consumo doméstico aunque algunas de ellas ya se encuentran inmersas en cadenas de valor internacionales. Las actividades de investigación y desarrollo suelen ser mínimas, ya que la mayoría de sus actividades son maduras, basadas en maquinaria importada y procesos estandarizados. A pesar del avance mostrado presentan bajos niveles de especialización y la competencia está basada en precios bajos.

Clusters basados en el procesamiento de recursos naturales: este tipo de clusters se desarrolla alrededor de la explotación de un recurso natural o agropecuario, actividades en las cuales en muchas ocasiones se alcanzan importantes escalas de producción, razón por la que en el desarrollo de este objeto se agrupan principalmente empresas grandes tanto del sector privado como del sector público, aunque también se pueden encontrar pequeñas y medianas empresas. 
Clusters de empresas de servicios intensivos en conocimientos: en este tipo de clusters se agrupan empresas cuyo objeto es la prestación de un servicio, algunas veces incentivadas por la legislación. Están basados en personal altamente calificado, promovido por capacitación vocacional y educación superior con capacidades para agregar valor. Entre ellos se encuentran los bancos y las zonas francas.

\section{Clusters dominados por empresas transna-} cionales: este tipo de cluster es típico en sectores de mayor contenido tecnológico como es el caso del sector automotriz y el electrónico donde las barreras a la entrada de nuevas empresas son bastante fuertes. Nace a partir del asentamiento de una subsidiaria de una empresa trasnacional en una locación diferente al país de origen, alrededor de la cual, a falta de competencia de los proveedores locales, se asienta todo un conjunto de proveedores internacionales que suministran la mayoría de los insumos requeridos por la empresa, donde la participación nacional se limita a actividades secundarias sencillas.

\subsection{Beneficios asociados a los clusters}

Aunque parezca contradictorio es en el actual contexto globalizado, en donde la localización y con ella las aglomeraciones empresariales ha retomado mayor importancia. Esto es así dado que son las condiciones sociales, económicas, políticas e institucionales presentes en el entorno nacional y local las que facilitan o limitan a las empresas en el desarrollo de ventajas competitivas que le otorgarán una posición privilegiada en el mercado (Altenburg, 2001; Porter, 1998; citado en Martin \& Sunley, 2003). En este contexto, las aglomeraciones han surgido como estructuras capaces de fomentar dinámicas como la cooperación inter-empresarial, la cual da lugar a la generación y transferencia de conocimiento y con ello a la innovación, considerados factores estratégicos para la competitividad en la actual sociedad del conocimiento. Todo lo anterior favorecido por la difusión de estudios de casos exitosos en países industrializados, de Europa y Estados Unidos, como el ya mencionado trabajo de Michael Porter, los cuales han llegado a permear las estructuras organizacio- nales y económicas de países periféricos como los de América Latina (Fernández y Vigil, 2007).

Las ventajas asociadas a los clusters suelen ser divididas en estáticas y dinámicas (Malmberg, Solvell, \& Zander, 1996), la presencia de éstas en un cluster depende del grado de desarrollo del mismo. Dentro de las ventajas consideradas estáticas se encuentran las relacionadas con el aprovechamiento de las economías de aglomeración asociadas según Marshall (1890) a la reducción en los costos de producción debido a la cercanía con proveedores, instituciones de apoyo y mano de obra especializada. Por su parte, las ventajas dinámicas están relacionadas con el desbordamiento, acumulación y transferencia de conocimiento sustentadas en relaciones de cooperación que jalonan con mayor rapidez procesos de innovación.

Autores como Schmitz (1995, citado por Altenburg, 2001) y Pietrobelli y Rabellotti (2005) enfatizan en la capacidad de las aglomeraciones para incrementar la eficiencia por medio de diferentes formas de articulación empresarial. Estos últimos, introducen el término "eficiencia colectiva" la cual se concibe como el resultado de la combinación de las economías externas positivas o eficiencia colectiva pasiva y la acción conjunta o eficiencia colectiva activa. En donde la primera integra las ya definidas economías de aglomeración y los beneficios asociados al derramamiento de conocimiento, y la segunda hace referencia a acciones deliberadas que se realizan de forma conjunta para el beneficio común.

Es importante aclarar que la eficiencia colectiva no es inherente al solo hecho de que las empresas se encuentren aglomeradas tal como lo plantean Pietrobelli y Rabellotti (2005), quienes consideran que el tiempo es una condición necesaria para el desarrollo de la misma, citando como ejemplo los distritos industriales en Italia, los cuales, en su mayoría tienen una larga tradición artesanal que permitió su desarrollo, aunque también afirman que la evidencia empírica aporta experiencias de aglomeraciones más recientes que surgieron debido al establecimiento de una empresa líder en una locación.

Por otra parte, Porter (1998, citado en Ketels 2003 y Corrales 2007) sustenta que los beneficios aso- 
ciados a los clusters se dan en tres amplías direcciones. Primero este tipo de estructuras favorece el incremento de la productividad de las compañías establecidas en el área a través del desarrollo de activos especializados y el suministro de materias primas e insumos en periodos más cortos de tiempo a aquellos que alcanzarían en aislamiento. Segundo las empresas $e$ instituciones ubicadas en una concentración pueden lograr mayores niveles de innovación sustentados en el derramamiento de conocimiento favorecido por la proximidad con clientes, compañías y proveedores dado que las ideas fluyen con mayor rapidez y existe una intensa presión por innovar. Y finalmente los clusters estimulan la formación de nuevos negocios dado que las barreras de entrada son menores, los inversores $e$ instituciones financieras locales están familiarizados con el tipo de actividades que se desarrollan dentro del cluster y existe un mercado local.

\subsection{Críticas al modelo de desarrollo basado en clusters}

Una de las críticas más estructuradas respecto al modelo de desarrollo basado en clusters la realizan Martin y Sunley (2003) quienes plantean algunos cuestionamientos de tipo teórico y empírico relacionados de manera particular con el trabajo de Michael Porter, quien como ya se ha mencionado en párrafos anteriores, introdujo el término cluster en la literatura económica. Martin \& Sunley (2003) parten de plantear el cuestionamiento de por qué la noción de Porter ha golpeado tan fuertemente el campo político cuando el fenómeno de las aglomeraciones no es reciente como quedó evidenciado anteriormente y cuando han habido trabajos más recientes realizados por geógrafos económicos, los cuales han sido ignorados, incluso por el mismo Porter. Así pues, se plantea que la noción de este autor no es más que una idea reciclada de los aportes de Marshall (1890) y otros autores, con la diferencia de que el éxito de sus planteamientos radica en la relación que el autor ha establecido entre el modelo de desarrollo basado en clusters y la competitividad a través del modelo del diamante.
La principal crítica que los mencionados autores plantean al concepto de cluster tiene que ver con la vaguedad de su definición en términos de escala geográfica y dinámica interna socio-económica, lo cual ha permitido a diferentes analistas usar este concepto de distintas maneras para satisfacer sus propios objetivos y ha dado lugar al surgimiento de diferentes tipologías para clasificarlos. Tal indeterminación es explicada a través de dos elementos: en primer lugar Porter (1991) plantea que las firmas en un cluster deben estar relacionadas de alguna manera sin llegar a precisar a qué tipo de relaciones se refiere, y segundo plantea que los clusters son grupos geográficamente próximos de compañías interrelacionadas sin precisar límites industriales ni geográficos. A lo que Porter (2003) agrega que los límites de un cluster están cambiando continuamente y están determinados por la profundidad del derramamiento de conocimiento. Sin embargo, estas debilidades encontradas en el concepto de cluster acuñado por Porter (1991, 2003) dificultan la identificación y promoción de los mismos, lo cual incide de forma directa en la formulación de políticas públicas.

Martin \& Sunley (2003) también plantean que hacen falta estudios que demuestren empíricamente los beneficios que comúnmente se han asociado a los clusters dado que existen trabajos que contradicen algunos de ellos, citando como ejemplo un estudio sobre la industria metalúrgica en Estados Unidos desarrollado por Harrison y otros (1996), el cual arrojó como resultado que no hay evidencia de que las firmas en concentraciones locales adopten nuevas tecnologías más rápidamente que sus contrapartes más dispersas geográficamente o aisladas.

Las críticas presentadas hasta ahora han estado relacionadas principalmente con la comprensión conceptual y la aplicación empírica del término cluster, sin embargo, hay otros planteamientos que han estado orientados a resaltar los aspectos negativos y contraproducentes de la proximidad geográfica que sin duda es la base de los clusters ${ }^{1}$. En este caso cabe mencionarse a Vega (2007), quien considera en primer lugar, que este tipo de estructuras pueden

5 Aunque existen estudios que plantean la existencia de clusters virtuales basados en tecnologías de información y comunicación en los cuales la proximidad deja de ser clave. 
fortalecer la conducta competitiva de tipo predatorio, esto es la competencia intensa entre empresas del mismo tipo o que atienden al mismo mercado; lo que presenta un grave problema particularmente para las empresas que apenas están comenzando en contraste con aquellos negocios que ya tienen un mercado establecido y relaciones tanto con proveedores como con consumidores específicos.

En segundo lugar, argumenta que la concentración puede fomentar la competencia por mano de obra calificada, dado que cabe la posibilidad de que algunas empresas traten de atraer personal calificado para fortalecer su propio capital humano, con el ofrecimiento de mayores sueldos, mejores condiciones de trabajo y vida, etc. Esta situación se presenta especialmente en industrias en las que la transferencia de capacidades humanas no tiene mayores dificultades, particularmente si dichas capacidades son fácilmente replicables.

En tercer lugar, el mencionado autor sostiene que los clusters pueden dar lugar a sobre-especialización lo cual incrementa las probabilidades de fracaso de una economía regional cuando el sector industrial se enfrenta a condiciones adversas. En cuarto lugar, plantea que la concentración de las empresas en una región específica puede dar lugar a saturación de los mercados e incentivar la competencia predatoria por precios deteriorando los procesos de innovación dado que las empresas estarán más enfocadas en tratar de competir con base en el precio que por la calidad del producto.

Así pues, tanto Martin \& Sunley (2003) como Vega (2007) consideran que el término cluster se ha convertido en una marca, la cual ha sido mucho más exitosa a pesar de la existencia de muchas otras teorías similares. Esto es como si Porter hubiera aplicado su teoría de estrategia competitiva o posicionamiento estratégico a sus propios planteamientos. $\mathrm{Y}$ finalmente advierten que se debe hacer un uso prevenido del modelo de desarrollo basado en clusters dado que así como es difícil determinar los factores de éxito de los clusters, estos se convierten en estructuras difícilmente replicables y por ello la política pública debe ser cuidadosamente formulada.
Al respecto, en este artículo se va a utilizar el concepto de cluster y particularmente los planteamientos de Porter (1991, 2003), sin desconocer las críticas suscitadas al respecto, teniendo en cuenta que si bien es un concepto ambiguo, beneficios derivados de la concentración geográfica y la proximidad, han sido identificados desde tiempo atrás. Adicionalmente, aunque la concentración se puede convertir en un aspecto negativo en un momento determinado, ello depende del direccionamiento estratégico del cluster y de la búsqueda de alternativas para hacerlo competitivo.

\section{Generación, acumulación y transferencia de conocimiento en aglomeraciones empresariales}

Las razones por las cuales las empresas toman la decisión de hacer parte de una aglomeración industrial han cambiado según la evolución de los factores que generan ventajas competitivas para las empresas, por ello los beneficios de concentración basados en costos han perdido influencia, y en contraposición aumenta la importancia de la posibilidad de encontrar capital humano especializado y una mayor facilidad para generar un ambiente dinámico de nuevo conocimiento (Salinas, 2004). Lo anterior se explica por el surgimiento de la economía del conocimiento, como factor productivo clave para generar valor agregado y potenciar procesos de innovación permanentes que busquen el desarrollo de las industrias, con lo cual el interés por la concentración empresarial toma fuerza como estrategia de cambio productivo y económico ya sea a nivel nacional, regional o local a partir de dinámicas de generación de conocimiento (Dahlman, 2007).

El conocimiento como factor creador de valor, está estrechamente ligado con las personas y las organizaciones siendo en algunos casos difícil de generar, transferir y apropiar (Malmberg, Solvell, \& Zander, 1996). Con lo anterior, en la creación del conocimiento es fundamental la integración social del individuo dentro de una organización, de forma que logre compartir sus conocimientos implícitos al resto del grupo; a esta acción Nonaka \& Takeuchi (1999) la denominaron socialización, donde el conocimien- 
to puede surgir en dos contextos, el primero en el nivel interno de la empresa a través de programas de capacitación o mediante los conocimientos previos del personal, y el segundo hace referencia a la generación de nuevo conocimiento a partir de redes de cooperación entre diferentes empresas quienes se asocian para emprender acciones encaminadas al desarrollo del mismo (Arias \& Morales, 2009). En este sentido, el proceso de generación y transferencia de conocimiento depende fuertemente de la proximidad entre individuos y empresas, y como afirma Zozaya (2006) el objetivo de transmisión de conocimiento en la sociedad no es sólo informar y difundir, sino también transformar el entorno en la búsqueda constante del quehacer innovativo y creativo.

La dinámica del conocimiento está determinada por los procesos de generación, desarrollo y transferencia del mismo; en la etapa inicial los datos e ideas son transformados en información que luego de ser procesada culmina en la creación de nuevo conocimiento, para ser apropiado de manera individual y ser finalmente trasferido por diferentes canales de comunicación en función de un ciclo constante de transformación y aplicación, en un proceso de interacción social, pues en palabras de Céspedes \& Martínez (2006) se debe generar la capacidad de traducir el conocimiento en capacidades, que a su vez depende del nivel de absorción del mismo y la disponibilidad del receptor para apropiarlo y compartirlo.

Desde la perspectiva de las aglomeraciones industriales se observa un alto grado de propensión a la concentración industrial a partir del proceso de transferencia de conocimiento de una empresa a otra, que a su vez depende del tipo de industria (Brenner \& Greif, 2006) y de conocimiento acumulado, haciendo una diferenciación entre las formas de conocimiento tácito y el codificado ${ }^{2}$; encontrando que cuando la industria percibe un grado ma- yor de conocimiento tácito las empresas buscan aglomerarse en mayor medida, pues en últimas la transferencia del mismo debe realizarse cara a cara con los diferentes eslabones de la cadena de valor y actividades conexas (Jonard \& Ozman, 2004), fomentando canales de información informales que aumentan la probabilidad de transmitir y absorber conocimiento entre los líderes empresariales y con un mayor grado entre personal de las diferentes empresas.

En cuanto a la capacidad de absorción tomando como referencia el desarrollo de Cowan, Jonard \& Ozman (2004) presentado en su estudio sobre dinámicas de conocimiento en una red industrial, dicha capacidad depende de factores tales como: el nivel de conocimiento previo, el grado de codificación, y la medida en que el emisor y el receptor comparten el conocimiento tácito. La dinámica de absorción de conocimiento aumenta cuando se recombina el conocimiento existente con el nuevo, así si el conocimiento existente es alto, mayor será la capacidad y disposición para adquirir nuevo conocimiento y generar procesos nuevos dentro de las empresas.

Con el fin de identificar factores que determinan el sistema de conocimiento dentro de un cluster, Bell \& Albu (1999) presentan un estudio sobre las características de la adquisición, generación y difusión del conocimiento en clusters de países en desarrollo, estableciendo ciertas características que al identificarse determina el sistema de conocimiento. Dichos factores se asocian a dos procesos: el primero hace referencia a la generación o adquisición de nuevo conocimiento, con ello se enmarcan las fuentes de conocimiento, canales de aprovisionamiento externo de conocimiento, el papel de las empresas en el aprendizaje interno y el tipo de aprendizaje; el segundo proceso es la difusión del conocimiento en el que se identifican factores como la base para la difusión de conocimiento entre las pequeñas y

6 El conocimiento es la capacidad de saber hacer ligada a las habilidades y/o a la capacidad de interpretación y utilización de conceptos. El conocimiento tácito hace referencia al saber hacer basado en la experiencia del propio trabajo, se caracteriza por ser difícil de codificar y transmitir, se configura como las destrezas informales y difíciles de definir captadas en el término "know-how"; y el conocimiento explícito o codificado está ligado a la comprensión es formal, perfectamente codificable y transmisible ya que es de fácil almacenamiento, entrenamiento o formación (Nonaka, 1991). 
medianas empresas, dirección de los flujos de conocimiento, el rol de las instituciones de enseñanza y tecnología y la participación de las empresas más grandes.

\subsection{Transferencia de conocimiento como fuente de concentración e innovación}

La innovación se define de acuerdo con el Manual de Oslo como la introducción de un nuevo o mejorado, producto, proceso, método de comercialización o método organizativo, en las prácticas internas de la empresa, la organización del lugar de trabajo o las relaciones exteriores (OCDE y EUROSTAT, 2006, p 17). Una característica común a todas las innovaciones es que deben ser introducidas en el mercado en el caso de la innovación de producto, y con respecto a las innovaciones de proceso, método de organización y comercialización, deben ser aplicadas en las operaciones de la empresa para identificarse como innovaciones.

Al realizar una revisión de literatura sobre los tipos de innovación que se pueden generar se encuentran las siguientes clasificaciones como orientación para la identificación de la innovación (ver tabla 2).

Tabla 2. Tipos de innovación por enfoque ${ }^{3}$

\begin{tabular}{|l|l|}
\hline \multicolumn{1}{|c|}{ PERSPECTIVA } & \multicolumn{1}{c|}{ CLASIFICACIÓN } \\
\hline $\begin{array}{l}\text { Según el objeto de la innova- } \\
\text { ción (Porter, 2003; OCDE y } \\
\text { EUROSTAT, 2006) }\end{array}$ & $\begin{array}{l}\text { De producto: creación de un nuevo producto o modificación de las características de los productos } \\
\text { existentes. } \\
\text { De proceso: desarrollo e implementación de nuevos procesos tanto en lo referente a la organiza- } \\
\text { De insumos: modificación de las características o uso de nuevos materiales. } \\
\text { De mercado: descubrimiento de demandas insatisfechas y segmentos de mercado. }\end{array}$ \\
\hline $\begin{array}{l}\text { Según el impacto de la inno- } \\
\text { vación, desde la teoría evolu- } \\
\text { cionista (Buitelaar, 2000) }\end{array}$ & $\begin{array}{l}\text { Innovaciones incrementales (continuas): hace referencia a un proceso acumulativo de pequeñas } \\
\text { mejoras (Alburquerque, 2006) que incrementan la eficiencia de los procesos o la calidad de los } \\
\text { Innovaciones radicales (rupturistas): cambio definitivo en la ejecución de un proceso o en las ca- } \\
\text { racterísticas de un producto. } \\
\text { Cambios en el sistema las cuales afectan varias industrias. } \\
\text { Cambios de paradigma que afectan economías enteras. }\end{array}$ \\
\hline $\begin{array}{l}\text { Según el origen de la Inno- } \\
\text { vación (Malaver \& Vargas, } \\
2004)\end{array}$ & $\begin{array}{l}\text { Externo: incorporada desde el exterior, desarrollada en otra locación, transferida e implementada. } \\
\text { Interno: generada a partir de las ideas de los miembros de la organización o bien a través de un } \\
\text { programa organizado de investigación y desarrollo. }\end{array}$ \\
\hline $\begin{array}{l}\text { Según el alcance de la inno- } \\
\text { vación (Malaver \& Vargas, } \\
2004)\end{array}$ & $\begin{array}{l}\text { Local } \\
\text { Nacional } \\
\text { Internacional }\end{array}$ \\
\hline
\end{tabular}

Para comprender la relación entre acumulación de conocimiento, concentración empresarial e innovación, se debe partir de ver la innovación como un proceso circular de interacción social que nace a partir de la generación y apropiación de nuevo conocimiento y se dirige continuamente hacia la producción, circulación y aplicación del mismo; con lo cual, la relación constante con el medio ambien- te, junto al desarrollo interno de la organización se configuran como componentes clave para generar procesos activos de acumulación de conocimiento que permitan potenciar actividades de innovación.

Dado el carácter social de los procesos de innovación, Alburquerque (2006) considera que éstos funcionan mejor cuando los actores se encuentran

7 Elaboración propia. 
cercanos entre sí, lo cual permite una interacción constante, una transmisión de información ágil y rápida favorecida por el hecho de que los actores comparten las mismas condiciones económicas, sociales, culturales, políticas e institucionales que facilitan el aprendizaje; en este contexto, la proximidad adquiere importancia en la medida en que estimule el aprendizaje y la innovación a través de la generación, transferencia y acumulación de conocimiento.

Diferentes estudios sobre clusters corroboran la apreciación de Alburquerque (2006), sobre el hecho de que las empresas que se encuentran aglomeradas exhiben mayor desempeño innovador, crecimiento y supervivencia que las empresas que no se encuentran dentro de una aglomeración (Brenner \& Greif, 2006; Cowan, Jonard \& Ozman, 2004; Gilbert, Mc Dougall \& Audretsch, 2008; OCDE, 1999) debido a la concurrencia tanto de fuerzas de competencia como de cooperación. Así mismo, Audretsch \& Feldman (1996) señalan los siguientes factores de aglomeración: la investigación y el desarrollo, la fuerza laboral especializada y calificada así como el tamaño de la ciencia básica para la industria específica. Dichas fuentes se convierten a su vez en la base para la generación de innovaciones que le permiten un mayor crecimiento a la aglomeración y la identificación como un territorio innovador que logre introducir cambios tecnológicos y estrategias gerenciales que fomenten la novedad en la industria a partir de la acumulación del conocimiento.

Con lo anterior, la generación de innovación estará en función del grado de absorción de conocimiento, el cual depende del nivel previo del mismo, la escala de codificación de dicho conocimiento y la forma en que el receptor y el emisor comparten conocimiento tácito, generando un doble flujo de conocimiento (Santos, Martínez \& Pajares, 2005). Como resultado se da la posibilidad de crear dinámicas de conocimiento encaminadas a su generación y posteriormente a la transferencia, concibiendo las condiciones propicias para el nacimiento de innovaciones que beneficien a las firmas concentradas.

Hay quienes sostienen que la innovación es más frecuente entre empresas de la misma industria y quienes sostienen que esto es así entre empresas de industrias diferentes. Al respecto en un estudio desarrollado por Maldonado (2004) se identifican estas vertientes. La primera es la de Marshall, Arrow y Romer, la cual, hace referencia al desbordamiento de conocimiento intra-industria, en el cual, el conocimiento acumulado por una empresa favorece el desarrollo tecnológico de empresas de la misma industria, sin embargo, la innovación en este contexto puede verse limitada debido a la ausencia de normas que protejan de manera efectiva los derechos de propiedad en un ambiente competitivo, lo que no sucede en un ambiente monopolístico en el cual, las externalidades pueden ser interiorizadas $y$ no pueden ser trasladas a otras empresas. Porter (2003) en la misma línea argumenta que la competencia local tiene el efecto de acelerar la imitación generando una presión hacia la innovación. La segunda vertiente, es el planteamiento contrario, donde autores como Jacobs (1969), sostienen que el desbordamiento de conocimiento se crea a partir de la producción de ideas entre empresas de diferentes sectores.

De acuerdo con Chaminade (1999) la competitividad de un cluster puede ser mejorada mediante el aumento de la capacidad y la calidad de la adquisición del conocimiento y los mecanismos de transferencia, lo cual implica que la mejora en los flujos de conocimiento puede elevar el nivel innovador de cualquier sistema. Por lo tanto, en un grupo donde la innovación se considera clave para la competitividad, este objetivo puede lograrse a través de políticas que se centren en el fomento de los flujos de conocimiento. De esta manera se observa la necesidad de examinar primero, la capacidad para adquirir, generar y transmitir el conocimiento en la aglomeración, desde las capacidades internas de cada empresa y la relación como cluster si se quiere mejorar la innovación y su desarrollo.

Finalmente, como se señaló antes la dinámica de creación y transferencia de conocimiento en las concentraciones empresariales es una causa directa de la innovación, pues ésta se crea a partir de conocimientos nuevos o transformación de los existentes, siempre y cuando exista un ambiente apropiado para el desarrollo de un sistema efectivo de conocimiento. Con lo anterior, en una aglomeración se busca inte- 
grar las personas, tecnologías y procesos con el objetivo de multiplicar la actividad para generar, capturar y usar conocimientos valiosos para cada empresa, transformándose en estructuras dinámicas absorción de conocimiento especializado, donde el desbordamiento del mismo se configura como una oportunidad de aprendizaje de las redes empresariales.

\subsection{Barreras para la generación, acumulación y transferencia de conocimiento e innovación}

En una aglomeración industrial se pueden encontrar factores internos y externos que impiden o dificultan la generación, acumulación y transferencia de conocimiento; los primeros se refieren al nivel intraorganizacional y el segundo al entorno global de la aglomeración -interempresarial-. Así el primero hace referencia a los temas específicos del proceso comunicación/ lenguaje /aprendizaje (Nooteboom, 2003; Zozaya, 2006) y el segundo se relaciona con las características propias del entorno y de los agentes que transfieren y reciben el conocimiento (Capello \& Faggian, 2005; Castro, Rocca y Ibarra, 2008; Malmberg, Solvell, \& Zander, 1996), este último aspecto está asociado con el nivel de cooperación y relaciones de confianza que puede existir entre las diferentes empresas.

El primer enfoque corresponde al proceso de producción y transferencia de conocimiento para la innovación de cada individuo, en cuyo caso se pueden presentar dificultades asociadas al grado de interdisciplinariedad que se maneje en la organización. El anterior suceso, según Nooteboom (2003), se define como aproximación cognoscitiva, entendida desde la capacidad de absorción de conocimiento y relacionada con la habilidad para comunicarse con los agentes que perciben y piensan de manera diferente; si el conocimiento que se tiene es muy próximo, es difícil generar un ambiente para la creación de nuevo conocimiento; es cuando se podría hablar de una excesiva proximidad cognitiva en referencia al conocimiento codificado entre cada empresa. Paralelamente se puede dar el fenómeno de la distancia cognoscitiva, donde los agentes tienen conocimiento muy distante $y$, por lo tanto, no es posible generar un aprovechamiento real del mismo, ya que códigos de lenguaje muy diferentes pueden generar barreras de comunicación o que no haya interés de apropiarlo por ninguno de los agentes.

Como se expuso anteriormente, cuando existe un componente mayor de conocimiento tácito en los flujos de información, la dinámica de acumulación de conocimiento como generador de innovación es más factible si los individuos o las empresas están cerca, debido a que la transferencia debe hacerse cara a cara. Sin embargo, cuando existe excesiva proximidad cognitiva, puede darse que los individuos y en general las firmas manejan el mismo nivel y contenido de conocimiento; con lo cual no habría un proceso real de aprendizaje y transformación, generando un estancamiento en la producción de nuevo conocimiento y por lo tanto de la innovación (Arias \& Morales, 2009).

El segundo enfoque que hace referencia a las características propias de los agentes que transfieren y reciben el conocimiento, generalmente tácito, donde se identifican dificultades con respecto a los bajos niveles de confianza por parte de los individuos para generar procesos de cooperación: orientaciones distantes en los objetivos organizacionales entre cada empresa (Castro, Rocca \& Ibarra, 2008), incapacidad de implementación de tecnología efectiva y la alta o baja movilidad del capital humano; esta última situación se explica asumiendo dos posibilidades, la primera es que los trabajadores no alcanzan a permanecer el tiempo suficiente para poder generar procesos de conocimiento y por ende de innovación estable, y la segunda hace referencia a que los trabajadores pueden permanecer bastante tiempo en las empresas y no lograr captar nuevo conocimiento del exterior que genere nuevas ideas (Malmberg, Solvell, \& Zander, 1996).

Zozaya (2006) corrobora lo expuesto anteriormente, cuando afirma que la efectividad de la comunicación entre redes para generar dinámicas de conocimiento exitosas, se da a partir del grado de acuerdo en los intereses del personal, líderes empresariales, investigadores, centros de investigación y demás instituciones conexas; alrededor del contenido y objetivos como: información y comunicación, planificación, cooperación, innovación, y servicios tecnológicos, entre otros. Las diferencias con respecto a los objetivos de los agentes están dadas en el tipo 
de conocimiento y las intencionalidades de su gestación y aplicación, factores que generarán las barreras para producir y difundir el conocimiento dentro de la aglomeración.

Finalmente, autores como Bell \& Albu (1999), llegan a la conclusión, de que en los clusters de países en desarrollo, son débiles las capacidades que se establecen para generar un sistema dinámico de conocimiento, mostrando para cada una de las características un desarrollo lento, limitando las iniciativas de innovación. Así mismo, se encontró que el desarrollo de clusters como sistema dinámico de conocimiento, también está en función del tipo de tecnología y las características básicas de la industria, las cuales pueden influir en el desarrollo de un cluster eficiente.

\section{Factores de competitividad en aglomeraciones empresariales}

Como se mencionó en párrafos anteriores, son varias las ventajas asociadas a las aglomeraciones empresariales, las cuales dependen en gran medida de la existencia de un entorno favorable para la cooperación. Sin embargo, como lo sostiene Vega (2007), es difícil determinar los factores de éxito en un cluster, dado que están asociados a condiciones propias del entorno y a las tendencias de evolución de cada caso particular. No obstante, autores como Vera \& Ganga (2007), señalan que los aspectos centrales que caracterizan los clusters exitosos son identificados desde la perspectiva de la calidad de sus interrelaciones, el objetivo de los vínculos y la acción conjunta para agregar valor.

Aunque no se tiene conocimiento acerca de la existencia de modelos especializados en la comprensión de los factores determinantes de la competitividad en aglomeraciones o clusters en el nivel local, para el análisis de la competitividad de la aglomeración objeto de estudio, se utilizó el modelo del diamante de Porter (1991). Lo anterior, en razón a su estrecha relación con este esquema de desarrollo y teniendo en cuenta que si bien, el objetivo del autor fue construir una teoría holística y general que contribuyera a la comprensión de los atributos na- cionales que fomentan las ventajas competitivas, él mismo, expresó que sus planteamientos pueden ser aplicados al estudio de unidades políticas o geográficas de menor entidad que toda una nación, como es el caso de una aglomeración en el nivel local.

De igual forma, se considera apropiado el uso de este modelo como marco de referencia, dado que el mismo, tuvo su origen en el hecho de que los sectores estudiados por Porter (1991) y que estaban alcanzando éxitos en el plano internacional, no se encontraban distribuidos homogéneamente en la geografía de la naciones, sino que por el contrario se encontraban localizados en áreas particulares. Así con este hallazgo fue que el autor estableció una estrecha relación entre la competitividad y la concentración geográfica de la actividad económica a partir de las dinámicas generadas de la misma, llegando inclusive a manifestar que el diamante de competitividad es la fuerza que permite desarrollar al cluster y simultáneamente el cluster es la manifestación espacial del diamante (Martin \& Sunley, 2003).

En síntesis, se considera pertinente la aplicación de este modelo para el análisis de la competitividad de la unidad objeto de estudio, dado que la misma es una concentración geográfica de empresas, en la cual se pueden identificar cada uno de los componentes del diamante y se puede argumentar que son éstos los que determinan su competitividad. El modelo del diamante se visualiza en la Ilustración 1 y sus componentes se describen a continuación.

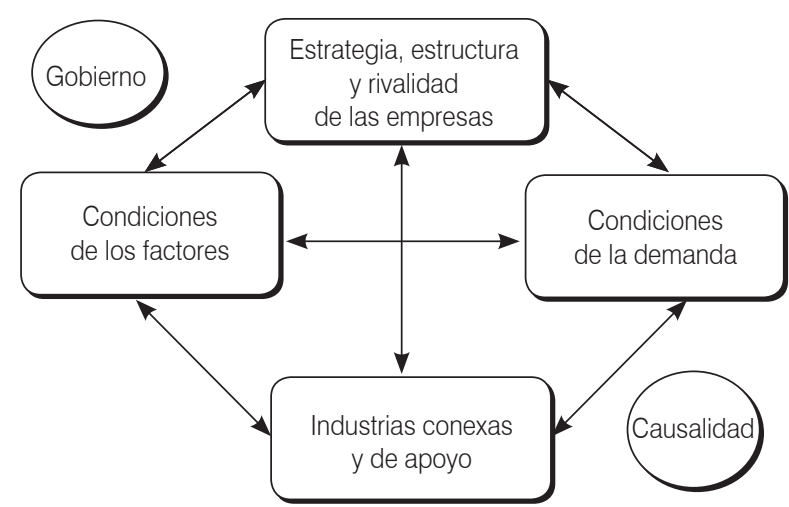

Ilustración 1. Componentes del modelo del diamante ${ }^{8}$

8 Porter (1991, 182). 
Condiciones de los factores: Este determinante hace referencia a la posesión de lo que tradicionalmente se conoce como los factores de producción, los cuales pueden ser asociados a cinco categorías: recursos humanos, recursos físicos, recursos de conocimiento, recursos de capital e infraestructura. Al respecto, pueden hacerse diferentes distinciones; según su origen, pueden dividirse entre factores heredados y factores creados, según su grado de evolución entre factores básicos y factores avanzados y finalmente de acuerdo a su especificidad, entre factores generalizados y especializados. Los factores que más contribuyen a crear ventaja competitiva son los factores creados, avanzados y especializados, ya que no todas las naciones los poseen puesto que su desarrollo exige inversiones cuantiosas y sostenidas tanto en capital como en recursos humanos y tecnología.

Condiciones de la demanda: Este componente hace referencia a la demanda interior de un producto, importante para la creación y mantenimiento de una ventaja competitiva en la medida en que le permite a las empresas percibir, interpretar, proyectar y ofrecer una solución a las necesidades del comprador, en donde lo primordial no es su cantidad sino su calidad; una empresa consigue ventaja competitiva si la demanda local le permite proyectar las necesidades futuras tanto del consumidor local como del extranjero de forma más rápida que la que lo hacen sus competidores exteriores.

Sectores conexos y auxiliares: Las empresas obtienen ventaja competitiva cuando cuentan en sus proximidades con un set de sectores auxiliares y complementarios competitivos internacionalmente, que se encuentran a la vanguardia de las innovaciones, lo cual permite un acceso eficaz, rápido e incluso preferencial a insumos más rentables en relación con su costo y favorece el hecho de que las empresas puedan compartir actividades, ejecutar procesos de manera más eficaz y coadyuvar al desarrollo de innovaciones compartidas.

Estrategia, estructura y rivalidad de las empresas: La rivalidad interior desempeña un papel estelar en los procesos de innovación y está influenciada entre otras cosas, por las prácticas de gestión de los líderes, quienes establecen la forma en que se manejan las relaciones con las entidades que tienen contacto con la empresa. Estas características se derivan de una u otra forma de las condiciones nacionales particulares como la idiosincrasia, el sistema educativo, la historia social, las estructuras familiares y un sin fin de variables intangibles pero forjadas con ímpetu en los individuos. Así mismo, por las diferencias en las metas que tratan de alcanzar las empresas de diferentes países, como en la motivación de sus empleados y directivos.

La casualidad: Esta variable hace referencia a sucesos o factores que están por fuera del control tanto de las empresas como del gobierno, dentro de las cuales se encuentran: actos de pura invención, importantes discontinuidades tecnológicas, discontinuidades en los costos de los insumos, cambios significativos en los mercados financieros mundiales o en los tipos de cambio, alzas insospechadas en la demanda mundial o regional, decisiones políticas de gobiernos extranjeros y guerras.

El gobierno: El rol de este actor es inevitablemente parcial dado que puede influir en los cuatro determinantes de la ventaja nacional pero carece de la capacidad de crearla por sí mismo. Son las empresas las que en última instancia deben hacer esta labor en comparación con sus rivales extranjeras.

\section{Diseño metodológico de la investigación}

La investigación que dio origen a este documento fue de tipo exploratoria, se enmarcó dentro de las ciencias sociales y tomó como método, el estudio de caso (Martínez, 2006). La investigación, tuvo como unidad de análisis la aglomeración de cuero, calzado y afines, ubicada en el Barrio Restrepo de Bogotá, perteneciente a la localidad Antonio Nariño. Sin embargo, se invitaron a participar en el estudio empresas pertenecientes a otras localidades limítrofes, aludiendo al hecho de que los clusters no tienen una delimitación geográfica específica, sino que su dimensión está determinada por las relaciones existentes entre las unidades económicas; por tanto se quería constatar el alcance de tales relaciones en dicha concentración empresarial. 
El objetivo de la investigación fue dar respuesta a los siguientes cuestionamientos: ¿la aglomeración estudiada es un cluster?, ¿Cómo son las dinámicas de acumulación de conocimiento, innovación y competitividad en la aglomeración objeto de estudio? ${ }^{9}$ Con el fin de dar respuesta a estos interrogantes se utilizaron tres técnicas para la recolección de información: la revisión de literatura especializada sobre el tema, la entrevista semi-estructurada y la encuesta por cuestionario. Las entrevistas tuvieron dos objetivos fundamentales, por un lado, recabar datos generales acerca de la industria y por otro, obtener información respecto a la aglomeración objeto de estudio, sus características y estructura de operación. Éstas fueron realizadas a los representantes de las asociaciones de la industria, las cuales fueron: Asociación Nacional del Sector del Calzado, el Cuero y Afines (ANSECALZ \& AFINES), la Asociación Colombiana de Industriales del Calzado, el Cuero y sus Manufacturas (ACICAM) y el Centro Tecnológico para la Industria del Calzado, Cuero y Afines (CEINNOVA).

La encuesta por cuestionario se orientó alrededor de cuatro elementos: información general de la empresa, gestión del conocimiento, innovación y competitividad, para un total de 92 preguntas. La aplicación de este instrumento se hizo tanto por vía directa como por vía indirecta, esto es; algunas veces fue diligenciada por un miembro del equipo de investigación a partir de las respuestas suministradas por el encuestado y en ocasiones fue el encuestado quien la diligenció personalmente. La encuesta fue aplicada a un grupo de empresarios pertenecientes a la aglomeración objeto de análisis.

\subsection{Selección de la muestra y casos de estudio}

El universo o población objeto de estudio fueron las empresas cuya actividad económica estaba relacionada con la industria del cuero, calzado y afines ubicadas en el Barrio Restrepo y barrios aledaños en donde se evidenciaba una gran concentración de las mismas; teniendo en cuenta las limitaciones de tiempo y recursos, se seleccionó una muestra de empresas por conveniencia, a partir de directorios empresariales publicados por la Cámara de Comercio de Bogotá y algunos elaborados para ferias especializadas. Así mismo, a partir de bases de datos aportadas por algunas de las asociaciones mencionadas y selección aleatoria en visitas al lugar.

La selección de las empresas se realizó teniendo en cuenta criterios como formalización, tiempo de operación igual o superior a cinco años y eslabón de la cadena productiva. El objetivo era que la muestra correspondiera con la distribución de las empresas en cada eslabón dentro de la aglomeración, teniendo en cuenta el censo realizado por la Cámara de Comercio de Bogotá, según el cual, el 5\% de las empresas ubicadas en esta localidad eran proveedoras de insumos, el 50\% estaban dedicadas a la transformación del producto y el $45 \%$ a la comercialización (Cámara de Comercio de Bogotá, 2007).

La muestra estuvo conformada por 63 empresas, a las cuales se envió invitación para que participaran en el estudio. Sin embargo, sólo 7 empresas diligenciaron satisfactoriamente el cuestionario, lo cual equivale al 11\% de las empresas convocadas, llevando esto a que la información se analizará más desde una metodología cualitativa y como estudio de caso, que desde una metodología cuantitativa y con muestra representativa. A partir de los resultados obtenidos se realizaron algunos análisis de frecuencias con el fin de determinar las características más prominentes en la aglomeración, sin perder de vista los resultados de otros estudios y lo expresado por los representantes de las asociaciones del sector en las entrevistas semi-estructuradas.

Teniendo en cuenta los mecanismos y criterios usados para la determinación de la muestra, es importante aclarar que hubo un sesgo en la misma, dado que ésta estuvo constituida en su mayoría por las empresas más representativas y con desempeño sobresaliente, teniendo en cuenta que eran éstas precisamente las que figuraban en los directorios y que coinciden con las empresas que hacen parte de las asociaciones mencionadas. Sin embargo, la calidad $y$ validez del estudio, se sustenta en que el sesgo se redujo, con el uso de diferentes fuentes de evidencia

9 Como se mencionó anteriormente el marco teórico para el análisis de competitividad es el modelo del diamante de Porter (1991). 
(Martínez, 2006), como fue el caso de la revisión de otros estudios sobre el sector, realizados por la Cámara de Comercio de Bogotá y el Departamento Nacional de Planeación, entre otros; así como la realización de entrevistas semi-estructuradas a los representantes de las asociaciones, quienes tienen una visión global del sector.

\section{Resultados}

Los resultados que se describen a continuación se derivan de dos fuentes; por un lado está la opinión de las asociaciones, quienes expresaron su visión global respecto a la aglomeración en conjunto; y por otro, los resultados obtenidos de las encuestas aplicadas a las empresas más representativas de la concentración empresarial, las cuales permiten tener una mirada parcial de la misma por la exclusión de otras empresas que muestran bajos niveles de competitividad y que no fueron incluidas en el estudio, dados los criterios establecidos en la selección de la muestra y la respuesta efectiva de los empresarios. De acuerdo con lo anterior, se encontraron algunas divergencias en los resultados de las entrevistas y las encuestas, las cuales serán evidenciadas en el documento.

\subsection{Estructura organizacional y características básicas de operación}

De igual forma que Porter (1991) evidenció en su estudio sobre la ventaja competitiva de las naciones, que las industrias no se distribuyen de manera homogénea en un territorio, sino que éstas tienden a concentrarse en determinadas ubicaciones; se encuentra que las actividades relacionadas con la industria del cuero, calzado y afines en Colombia se encuentran concentradas en ciudades particulares y más allá, en localidades específicas al interior de las mismas. Dentro de estas ciudades, Bogotá alberga una de las concentraciones más grandes y tradicionales en esta industria, la cual corresponde a la unidad objeto de estudio.

La aglomeración empresarial del Barrio Restrepo, es una concentración de origen espontáneo que se concibió a partir de las decisiones de localización de las empresas consideradas individualmente. Lo anterior, sin que existiera intervención de algún agente público o privado que lo incentivara o buscara a través de ello la consecución de un objetivo determinado.

Adicionalmente esta industria, es considerada tradicional (Morales, Sanabria \& Arias, 2009), dado que la mayoría de las empresas que la constituyen son empresas familiares en las cuales se desempeñan laboralmente varios miembros de una misma familia, así mismo, son empresas en las que el conocimiento es transmitido de generación en generación, esto es, de los padres a los hijos, siendo muy común que estos últimos se desempeñen desde edades muy tempranas en las empresas de sus progenitores. El carácter tradicional de la aglomeración se evidenció al indagar por las razones que motivaron a los empresarios a establecer su propia unidad de negocio, a lo cual el $52 \%$ respondió que lo hicieron para aprovechar los conocimientos que poseían a cerca de las actividades desarrolladas en el sector y algunos para dar continuidad a la tradición familiar. Tan solo el 42,9\% de los empresarios encuestados manifestó haber constituido la organización por vocación empresarial.

Partiendo de lo antes expuesto y de un estudio del Departamento Nacional de Planeación, se pueden identificar dos tendencias en las empresas que conforman la aglomeración; por un lado están aquellas de tipo tradicional que constituyen la mayoría, las cuales exhiben un débil enfoque gerencial asociado a bajos niveles de formación de los empresarios y en las cuales los procesos de producción son artesanales. Por otro lado, están algunas empresas nuevas constituidas por profesionales egresados de carreras como diseño industrial y administración de empresas, quienes han encontrado atractivo establecer unidades de negocio en actividades como fabricación de calzado, marroquinería e importación de insumos, alcanzado altos niveles de competitividad (Departamento Nacional de Planeación, 2007).

Así mismo, se pudo evidenciar que es una aglomeración constituida principalmente por micro y pequeñas empresas, en donde las medianas y grandes tienen poca participación (Morales, Sanabria \& Arias, 2009). De acuerdo con los criterios establecidos por la Ley 905 de 2004, del total de la empresas que constituyen la aglomeración, el 42,9\% son microempresas y el $57,1 \%$ pequeñas empresas. 
De igual forma, el estudio reveló que el tipo de sociedad más común en la misma, son la sociedades unipersonales con una participación del 71,4\% del total de las empresas analizadas, y una participación del 14,3\% de sociedades anónimas y empresas de responsabilidad limitada respectivamente, lo cual puede dar un indicio del volumen de capital y la disposición para la asociación que exhiben las organizaciones que conforman esta aglomeración.

De manera relacionada, se encontró que existe un alto porcentaje de informalidad, del cual no se conocen datos exactos, dado que las empresas informales frecuentemente se camuflan en el ambiente y suelen aparecer y desaparecer en periodos cortos de tiempo (Morales, Sanabria \& Arias, 2009). Este fenómeno impacta de manera significativa la competitividad del sector, debido a que las empresas informales pueden ofrecer productos a un menor precio, asociados a unos costos más bajos que las empresas debidamente legalizadas. Al respecto se conoce que estos empresarios prefieren permanecer bajo la penumbra de la informalidad que asumir mayores costos asociados principalmente a la nómina de los trabajadores - prestaciones sociales de ley, seguridad social y parafiscales, e impuestos. Esta conducta es a la vez propiciada por los empleados del sector, quienes sostienen que así pueden recibir un mayor salario y no están sujetos a descuentos de ningún tipo. También, manifiestan que hay ausencia de programas y políticas por parte del Estado que incentiven a estas empresas a salir del anonimato y los pocos mecanismos que existen requieren procedimientos tediosos que ningún empresario está dispuesto a asumir.

Asociado al tamaño de las empresas y a los bajos niveles de formación de los empresarios, se encontró que la mayoría de ellas no tiene una estructura funcional definida (Morales, Sanabria \& Arias, 2009), por tanto las decisiones se toman de manera centralizada por el dueño de la empresa, quien además de dirigirla está encargado de funciones relacionadas de manera directa con el proceso productivo, como es el caso del control de calidad del producto terminado. Así mismo, se encarga de funciones de apoyo como compra de materiales e insumos, selección de personal, mercadeo y ventas, entre otras. Este hecho incide directamente en que los empresarios manifiesten no tener tiempo para hacer parte de agremiaciones $\mathrm{u}$ asociaciones del sector, ni para establecer redes de cooperación con otros empresarios o participar en estudios, dado que esto implicaría una disposición de tiempo con el que ellos no cuentan, para asistir a reuniones y eventos.

En la aglomeración se pueden encontrar empresas pertenecientes a los diferentes eslabones de la cadena productiva a excepción de las curtiembres y la fabricación de maquinaria. Dentro de los eslabones que se pueden encontrar se tienen fabricantes, importadores, distribuidores y comercializadores de insumos, fabricantes de calzado para todos los segmentos del mercado, fabricantes de marroquinería, distribuidores y comercializadores de producto final y consumidores. Cabe destacarse la función realizada por las peleterías, las cuales son almacenes que distribuyen toda clase de insumos, desde pieles hasta pegantes, accesorios, hilos, etc., tanto de origen nacional como importado. El uso de estos insumos depende de la colección que realice cada fabricante. La Ilustración No. 2 muestra la composición y la relación actual entre los elementos de la aglomeración, los cuales serán descritos posteriormente.

Insumos: El principal insumo utilizado por la industria es el cuero, el cual se puede obtener de la piel de especies mayores, esto es los bovinos, especies menores como los caprinos y los porcinos y especies exóticas como el cocodrilo. Adicionalmente se utilizan materiales textiles y sintéticos, herrajes, cremalleras, botones, hilos, hebillas, pegantes, marquillas, suelas, entre otros.

Líneas de producción: En la aglomeración se pueden encontrar fabricantes de calzado para cualquier segmento del mercado. Para caballero, dama, niño, tanto sport como formal. Así como fabricantes de productos agrupados bajo la categoría de marroquinería como prendas de vestir, bolsos, maletas, maletines, billeteras, cinturones, guantes, entre otros y fabricantes de productos hechos en lona.

Comercialización: La comercialización del producto final es realizada a través de diferentes canales: establecimientos propios, almacenes de cadena, boutiques, almacenes especializados y grandes superficies. 


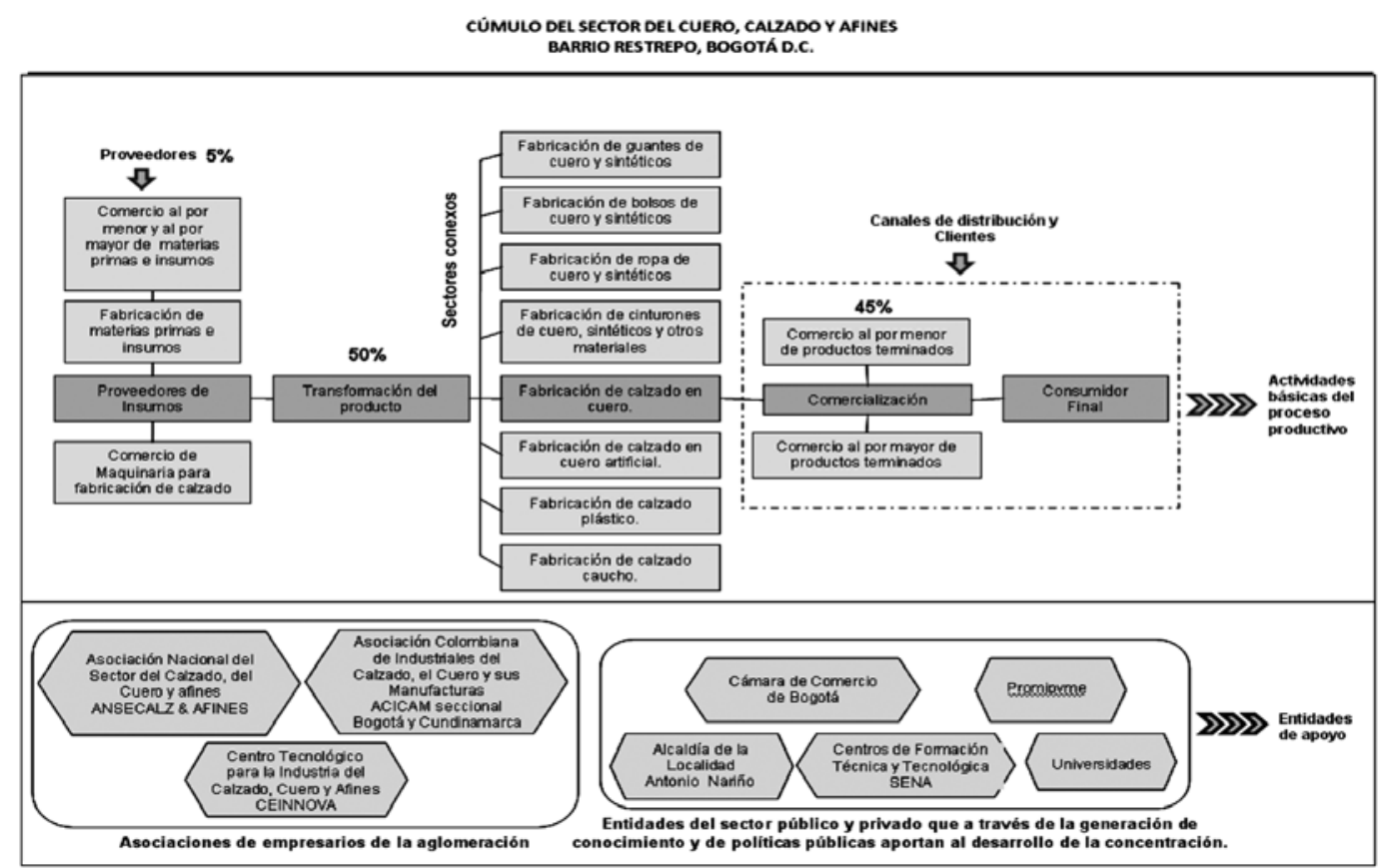

Ilustración 2. Eslabones y distribución de empresas en la cadena de cuero y calzado ${ }^{10}$

Respecto a la distribución de las empresas en los diferentes eslabones de la cadena, no existen datos ciertos, precisamente debido a fenómenos como la informalidad y la constante dinámica de apertura y cierre de empresas en cortos periodos de tiempo. Sin embargo, como se mencionó anteriormente, se puede hacer una aproximación a partir de un estudio presentado por la Cámara de Comercio de Bogotá en el 2007, el cual revela que 50\% de las empresas pertenecen al eslabón de transformación, $45 \%$ a la comercialización y el 5\% son proveedores de insumos. En lo que respecta a las empresas estudiadas el $57,1 \%$ estaban relacionadas con actividades transformación y comercialización del producto y el restante con la proveeduría de insumos para la industria.

El 71,4\% de los productos que se transan en esta aglomeración son de gama baja y media, evidenciando la existencia de productos de baja calidad y baja diferenciación, lo cual ha conllevado a sustentar la competencia a través de los precios. Dichos productos están dirigidos principalmente a satisfacer el mercado interno aunque algunas empresas han incursionado en mercados extranjeros como Venezuela y Ecuador, entre otros (Sanín \& Sierra, 2005). Sin embargo, la demanda de estos países no se considera segura ya que regularmente las exportaciones se ven afectadas por problemas políticos y de relaciones exteriores entre los países, frente a lo cual se hace necesario abrir la oferta hacia mercados en Centro América y Europa.

Finalmente es importante resaltar la presencia de tres asociaciones que aunque no tienen una amplia cobertura en la aglomeración, por factores como la falta de motivación por parte de los empresarios y la ausencia de coordinación efectiva entre las mismas, mantienen lazos con algunos empresarios que lo consideran beneficioso.

\subsection{Acumulación de conocimiento como factor de innovación en la aglomeración del cuero, calzado y afines}

De acuerdo con la revisión conceptual de aportes realizados por diferentes autores (Audretsch \& Feld-

10 Adaptado por las autoras de Cámara de Comercio de Bogotá (2007). 
man, 1996; Bell \& Albu, 1999; Castro, Rocca y Ibarra, 2008; Cowan, Jonard \& Ozman, 2004; Gilbert, Mc Dougall \& Audretsch, 2008; Malmberg, Solvell, \& Zander, 1996), en general, para que exista una efectiva generación y transferencia de conocimiento como factores propicios para la creación de un ambiente innovador, es necesario un contexto de cooperación entre empresas y apropiación de conocimiento efectivo en términos de uso de tecnología, investigación y disponibilidad real para trasmitir por canales eficientes todo tipo de información, que se convierta en conocimiento tácito o explicito, reforzado por la proximidad geográfica de las empresas.

Con el fin de indagar por el proceso de acumulación de conocimiento como motivador de un ambiente innovador en la aglomeración y tomando como referentes los planteamientos de Cowan, Jonard \& Ozman (2004) y Bell \& Albu (1999), se realizaron preguntas relacionadas con la generación y transferencia de conocimiento, así como concernientes al proceso de innovación que realizan las empresas pertenecientes a la aglomeración. En la primera parte se averiguó por temas relacionados con el nivel de formación del personal (con el objetivo de identificar el nivel y especialización del conocimiento previo en términos del tipo de educación formal adquirida) ${ }^{11}$, el tipo de conocimiento más frecuente y las fuentes por medio de las cuales adquieren conocimiento ${ }^{12}$, así mismo se buscó identificar si se generan redes efectivas a partir de procesos de cooperación, identificado dinámicas de red de conocimiento.

\subsubsection{Nivel de conocimiento previo y tipo de conocimiento predominante:}

En relación con el nivel de formación de los administradores o gerentes de las empresas (ver Ilustración 3), los resultados muestran que hay un alto grado de educación formal, la cual en su mayoría está asociada con estudios en gerencia de diseño industrial y de modas, permitiendo a las organizaciones que cuentan con este personal, tener un mayor desarrollo con respecto al resto de empresas que pertenecen a la aglomeración ${ }^{13}$. En cuanto a la formación del nivel operativo; a diferencia del administrativo, se observa una alta participación de personal que solo cuenta con estudios de primaria seguida del bachillerato, explicando el nivel de adiestramiento en términos operativos y de tareas que implican procesos manuales (Morales, Sanabria \& Arias, 2009).

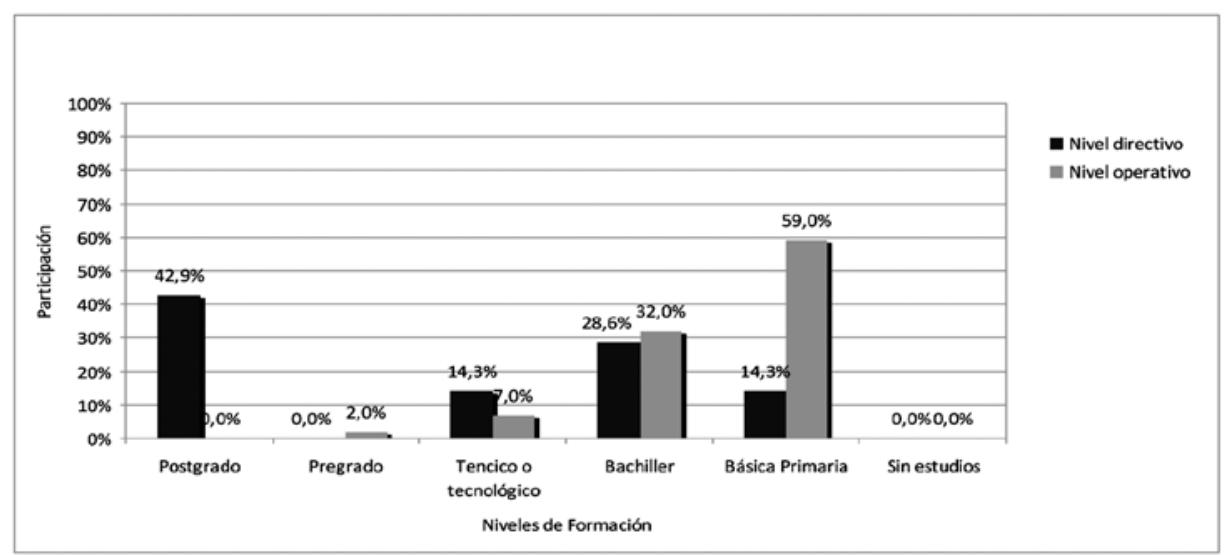

Ilustración 3. Nivel de formación del recurso humano de la aglomeración ${ }^{18}$

11 Según el planteamiento de Cowan, Jonard \& Ozman (2004) la dinámica de absorción de conocimiento aumenta cuando se combina el conocimiento existente con el nuevo, así si el conocimiento existente es alto, mayor será la capacidad para adquirir nuevo conocimiento y generar procesos dirigidos a la innovación dentro de las empresas.

12 Con el fin de describir la manera en que se genera conocimiento dentro de las empresas.

13 Los resultados están sujetos a la selección de la muestra que como característica tienen el estudio de las empresas más representativas de la aglomeración y por ende las de mayor desarrollo, dado en algunos casos por el mayor nivel de formación de los empresarios quienes están más dispuestos a participar en este tipo de estudios.

14 Elaboración propia. 
Según los datos de las encuestas, el personal dedicado a labores operativas tiene procesos de aprendizaje impulsados por la rutina de observación de las tareas, hecho que se reafirma cuando se indaga por las fuentes por medio de las cuales el nivel operativo adquiere conocimiento, pues se encontró que el $71.4 \%$ de las empresas encuestadas manifestaron que el personal lo adquiere principalmente a través de la experiencia en otras empresas de la aglomeración, en menor medida a través de la enseñanza familiar con un $42.9 \%$ y las capacitaciones internas con el 57.1\%. Sin embargo, los empresarios declaran que dichas capacitaciones se realizan de manera esporádica y no obedecen a un plan de capacitación y desarrollo formalmente establecido. Otras fuentes de conocimiento como capacitaciones de asociaciones, centros de formación, revistas y publicaciones, no son usualmente utilizadas como fuente de conocimiento. Con lo anterior se puede deducir que el nivel de conocimiento tácito en la aglomeración es alto en función de la experiencia del personal.

Adicionalmente, siguiendo el planteamiento de Cowan, Jonard \& Ozman (2004), al existir un conocimiento previo no tan elaborado en términos del nivel de educación formal y la experiencia dada por la observación rutinaria de procesos, la dinámica de absorción de conocimiento en la aglomeración se ve limitada, pues la disposición para recombinar nuevo conocimiento es débil y hace parte de las razones por las cuales el proceso para generar innovaciones se torna difícil.

\subsubsection{Fuentes de conocimiento en función de los tipos de innovación:}

Utilizando los tipos de innovación que indica el Manual de Oslo (OCDE y EUROSTAT, 2006), con el fin de identificar las fuentes de conocimiento en función de los tipos de innovación, se preguntó sobre la frecuencia con la cual se utilizan ciertas fuentes, encontrando que en cuanto a la elaboración del producto, las fuentes más utilizadas son los proveedores, clientes y revistas especializadas. En lo que respecta a la forma de organización y mercadotecnia, las fuentes más prominentes son los clientes y competidores nacionales e internacionales, en contraste, las fuentes con menor utilización son la consultoría o asesoría de expertos y los centros de formación y universidades como se ilustra en la tabla 3.

Tabla 3. Fuentes de conocimiento según el tipo de innovación ${ }^{15}$

\begin{tabular}{|l|r|c|c|c|}
\hline \multicolumn{1}{|c|}{ FUENTES DE CONOCIMIENTO* } & INSUMOS & PRODUCTO & ORGANIZACIÓN & MERCADOTECNIA \\
\hline Proveedores & $100 \%$ & $100 \%$ & $17 \%$ & $50 \%$ \\
\hline Clientes & $100 \%$ & $57 \%$ & $33 \%$ & $33 \%$ \\
\hline Revistas & $33 \%$ & $57 \%$ & $17 \%$ & $17 \%$ \\
\hline Competidores Nacionales & $0 \%$ & $57 \%$ & $50 \%$ & $33 \%$ \\
\hline Competidores internacionales & $33 \%$ & $29 \%$ & $50 \%$ & $50 \%$ \\
\hline Estudios de Mercado & $33 \%$ & $43 \%$ & $33 \%$ & $17 \%$ \\
\hline Patentes & $0 \%$ & $14 \%$ & $17 \%$ & $17 \%$ \\
\hline Empleados & $50 \%$ & $29 \%$ & $17 \%$ & $17 \%$ \\
\hline Centros de formación y Universidades & $0 \%$ & $0 \%$ & $33 \%$ & $0 \%$ \\
\hline Ferias de Negocios & $0 \%$ & $43 \%$ & $50 \%$ & $67 \%$ \\
\hline Asociaciones y Agremiaciones & $0 \%$ & $0 \%$ & $33 \%$ & $33 \%$ \\
\hline Consultoría o asesoría de expertos & $0 \%$ & $0 \%$ & $0 \%$ & $0 \%$ \\
\hline
\end{tabular}

15 Elaboración propia. Porcentajes calculados sobre el total de empresas encuestadas. 
Los resultados muestran que a pesar de que la aglomeración cuenta con algunas instituciones conexas que pueden ser fuente importante de conocimiento, estas no se configuran aún como un apoyo oportuno y habitualmente usado por las empresas, pues estas últimas prefieren adquirir información de manera más informal por medio de clientes, proveedores y competidores, y con menor utilización las ferias de negocios y agremiaciones o asociaciones, las cuales, para la mayoría, solo son utilizadas para adquirir nuevo conocimiento sobre procesos directivos. Lo anterior, puede influir en la tendencia de los empresarios a apropiar productos o procesos ya elaborados, que son modificados en cierto grado, ${ }^{20}$ pero que no necesariamente implican una innovación, acentuando en algunos casos la cultura de la imitación.

\subsubsection{Procesos de cooperación como estrategia para compartir conocimiento:}

Se indagó si las empresas encuestadas en algún momento han realizado algún tipo de alianza, ya sea con competidores o con entidades de apoyo, esto con el fin de identificar procesos o iniciativas de cooperación dentro de la aglomeración. Los resultados muestran que para el estudio de caso, el 71.4\% del total de empresas nunca han generado iniciativas de alianzas o de cooperación. También se identificó que las razones principales por las cuales no se dan iniciativas de cooperación, son la falta de confianza, baja lealtad en los acuerdos informales entre empresarios, actitud individualista, poca permanencia en proyectos de largo plazo conjuntos, divergencia de intereses y estrategias de negocio, además del incremento de los costos de control. Lo antes expuesto, corrobora los resultados del anterior apartado en el que se identifica una baja participación de las asociaciones del sector, centros de formación y universidades, así como competidores como fuentes de información para las empresas. Estos resultados, muestran la poca disposición para compartir o transferir conocimiento entre las organizaciones que hacen parte de la aglomeración, limitando el flujo del nuevo conocimiento que se puede generar a partir de la interacción.

\subsubsection{Características generales del sistema de conocimiento de la aglomeración:}

Retomando la identificación de características de los sistemas de conocimiento propuestas por Bell \& Albu (1999) se presenta el estado de la dinámica de conocimiento en la aglomeración (ver tabla 4). Se observa que el sistema de conocimiento de la aglomeración aún es débil y debe fortalecerse a partir de políticas de flujo de conocimiento y actividades de cooperación entre las entidades de apoyo, la cadena de valor (clientes y proveedores) y los competidores; pues en la situación actual, el sistema no genera condiciones propicias para dinámicas sistemáticas de transferencia y generación de conocimiento, motivado en la poca gestión del conocimiento dentro de cada empresa y a nivel de aglomeración, inhibiendo las actividades para la innovación, pues no se tiene una dinámica fuerte en producción de nuevo conocimiento, que es el insumo para las innovaciones.

\subsubsection{Factores que dificultan la generación y acumulación de conocimiento:}

Según los resultados encontrados, los factores que interrumpen la dinámica de acumulación de conocimiento y la innovación en la aglomeración de estudio se asocian principalmente a la cultura de los empresarios (Castro, Rocca \& Ibarra, 2008) y en general al tipo de producción tradicional de la industria; es decir, se relacionan con las características propias de las acciones de los agentes que transfieren y reciben el conocimiento (Malmberg, Solvell, \& Zander, 1996). De acuerdo con las asociaciones del sector y los empresarios encuestados, se lograron identificar las siguientes barreras u obstáculos para la acumulación de conocimiento e innovación en la aglomeración:

16 En el caso de los productos, el valor agregado según los empresarios se da generalmente en diseño. 
Tabla 4. Características del sistema de conocimiento de la aglomeración ${ }^{17}$

\begin{tabular}{|c|c|}
\hline $\begin{array}{l}\text { CARACTERÍSTICAS } \\
\text { ORGANIZACIONALES }\end{array}$ & DESCRIPCIÓN \\
\hline \multicolumn{2}{|c|}{ A. Con respecto a la difusión y transferencia del conocimiento intra-cluster } \\
\hline $\begin{array}{l}\text { 1. Base para la difusión entre las peque- } \\
\text { ñas empresas }\end{array}$ & $\begin{array}{l}\text { Se da por la proximidad espacial y no se caracteriza por procesos de cooperación. La } \\
\text { difusión del conocimiento es pasiva, pues no existen planes ni programas formales. }\end{array}$ \\
\hline $\begin{array}{l}\text { 2. La dirección dominante de los flujos } \\
\text { de conocimiento }\end{array}$ & $\begin{array}{l}\text { Es vertical dado que se realiza a través de enlaces entre clientes y productores y pro- } \\
\text { veedores, y no entre competidores. }\end{array}$ \\
\hline $\begin{array}{l}\text { 3. El papel de los institutos de tecnología } \\
\text { y formación }\end{array}$ & $\begin{array}{l}\text { No se configuran como una fuente de conocimiento importante, dado que no son usual- } \\
\text { mente utilizados. Tienen un rol casi pasivo. }\end{array}$ \\
\hline $\begin{array}{l}\text { 4. El rol de las empresas más grandes } \\
\text { de la aglomeración }\end{array}$ & $\begin{array}{l}\text { Toman una función pasiva, y no estructurada en cuanto a la difusión de nuevas tecno- } \\
\text { logías y procesos para la aglomeración. }\end{array}$ \\
\hline \multicolumn{2}{|c|}{ B. Relacionadas con la adquisición o generación de nuevos conocimientos } \\
\hline $\begin{array}{l}\text { 5. Fuentes de conocimiento interno o } \\
\text { externo en las empresas/ aglomeración. }\end{array}$ & $\begin{array}{l}\text { Alta proporción de fuentes externas a la empresa, pues las fuentes de mayor utilización } \\
\text { corresponden a clientes y proveedores. Se identifica que la gestión de nuevo conoci- } \\
\text { miento dentro de las empresas es baja. Igualmente en el nivel de la aglomeración, las } \\
\text { organizaciones de apoyo que la conforman no aportan significativamente a la genera- } \\
\text { ción de conocimiento nuevo, porque son poco utilizadas. }\end{array}$ \\
\hline $\begin{array}{l}\text { 6. Canales para el aprovisionamiento ex- } \\
\text { terno de conocimiento }\end{array}$ & Canales limitados e informales \\
\hline $\begin{array}{l}\text { 7. Rol de las empresas en el aprendizaje } \\
\text { interno }\end{array}$ & $\begin{array}{l}\text { El papel de las empresas es pequeño, pues no hay procesos o planes de formación } \\
\text { estructurados y formales para el recurso humano. }\end{array}$ \\
\hline 8. Tipo de aprendizaje & Alta proporción de conocimiento tácito dado por la experiencia y el quehacer diario. \\
\hline
\end{tabular}

- Bajo nivel de desarrollo tecnológico: Hay pocas empresas que incorporan tecnología en sus procesos (Sanín \& Sierra, 2005), dado la alta inversión que deben realizar y que para el caso de las micro y pequeñas empresas no logran tener una base financiera sólida para soportarla, así como la cultura de la producción tradicional o manual, haciendo que los empresarios sean reacios a los cambios.

- La demanda interna no es exigente: Lo que hace que las empresas no vean necesaria la evolución de sus procesos productivos y de comercialización, generando un estancamiento en el desarrollo del producto. Al respecto se indagó por el nivel de exigencia de los clientes en términos de calidad y de acuerdo al tipo de producto; encontrando que las empresas que manejan un portafolio de gama alta consideran que la demanda con respecto a la calidad es muy exigente, mientras que las empresas cuyo producto es de gama media indican que la demanda es medianamente exigente, por el contrario las empresas cuyo producto es de gama baja identifican que la demanda no es exigente, esto explica el grado de desarrollo de sus productos que en general para la aglomeración se destacan por ser de gama baja y media. En el caso de las empresas que desarrollan actividades de exportación un $57.1 \%$ considera que la demanda externa es más exigente que la demanda interna y están de acuerdo que al no ser

17 Adaptado por las autoras a partir de Bell \& Albu (1999). Porcentajes calculados sobre el total de empresas encuestadas. 
los clientes exigentes, es difícil que las empresas se vean presionadas por generar innovaciones que permitan diferenciarse en el mercado.

- Baja capacidad gerencial de los directivos de empresa: Los estudios realizados por las asociaciones de la aglomeración han evidenciado debilidad en diseño y desarrollo, ingeniería de procesos, gestión gerencial y marketing estratégico; explicado por una gerencia empírica, en algunos casos con visión de corto plazo y donde la administración es netamente centralizada; lo anterior genera como consecuencia estructuras organizacionales débiles o inadecuadas (Morales, Sanabria \& Arias, 2009). Afirmaciones sustentadas además en que el $57.1 \%$ de las empresas estudiadas, manifiesta que no están divididas en áreas funcionales, mostrando que no cuentan con una estructura organizacional fuerte en términos de división del trabajo, explicado también porque la aglomeración en su mayoría está compuesta por micros y pequeñas empresas que tienen grupos de personal pequeños.

Adicionalmente, se observa el fenómeno de la polifuncionalidad de los administradores o gerentes de empresa pues el $71.4 \%$ de las empresas encuestadas afirman que las decisiones se toman de manera centralizada, sustentada además por la falta de división de las funciones, mostrando en algunos casos un limitante importante en cuanto a la toma de decisiones rápidas y efectivas con las cuales debe contar la empresa.

- Existe un alto grado de rotación de personal: Se observa un bajo interés en la gestión interna del conocimiento en las empresas, medida en el desarrollo integral de la mano de obra, pues esta no permanece lo suficiente, como para generar procesos de generación de conocimiento e innovación continuos, atribuido a las condiciones laborales que son de tipo informal y sustentadas en el pago a destajo, con lo que los trabajadores rotan constantemente entre las empresas de la aglomeración, pues el $42.9 \%$ de las empresas estudiadas manifes- taron que el empleado más antiguo en el nivel operativo ha permanecido en la empresa entre 5 y 10 años, mientras que el porcentaje restante se distribuye de manera uniforme entre una periodicidad menor a 3 meses y dos años. Así mismo el $42.9 \%$ de las empresas encuestadas expresaron que la frecuencia con la cual se vinculan nuevos empleados a la organización es semestral, seguida de trimestral y semanal con un $28.6 \%$ respectivamente, el $14.3 \%$ manifestaron que anualmente y cada que se requiere.

De acuerdo con el referente teórico de esta investigación, lo anterior, no permite un ambiente claro en el que se cree un sentido de pertenencia con las empresas por parte de los trabajadores, con lo cual solo se limitan a seguir ordenes sin generar espacios para generar ideas nuevas convirtiéndose en procesos mecánicos y sin alta exigencia de especialización que aporte a la creación de innovaciones.

- Baja diferenciación en los productos: Se atribuye a la cultura de la imitación ya sea de tipo local o externa; hay pocas empresas que cuentan con personal especializado en el diseño de producto, factor que hasta ahora empieza a desarrollarse en la aglomeración dada la presión de la competencia. Los empresarios manifiestan no vincular a su planta de personal, profesionales como diseñadores industriales, dado que no pueden asumir los costos asociados y por ello prefieren obtener sus diseños de internet o revistas especializadas; afirmando que finalmente los diseños son copiados por los competidores, lo cual lleva a una escasa diferenciación de producto, que conduce hacia una competencia en precios.

- Limitados recursos para investigación y desarrollo: Para el caso de las micro y pequeñas empresas los recursos financieros son escasos para hacer investigación y por ende disfrutar de los beneficios de la innovación (Morales, Sanabria \& Arias, 2009). Aunque el gobierno a través de algunos programas de fortalecimiento de la industria ofrece ayuda financiera, muchas de las empresas pequeñas no 
logran acceder a ellos, debido a la cantidad de requisitos impuestos para tal fin, adicionalmente las actividades de investigación están más asociadas a procesos de benchmarking enfocados al desarrollo del producto en diseño y están a cargo de un grupo muy pequeño en la empresa o una sola persona, como se identificó en el apartado anterior.

- Baja disposición a participar en procesos cooperativos: Se identifica una limitada cooperación entre las empresas aglomeradas, hecho que tiene su origen en: la falta de confianza, baja lealtad en los acuerdos informales entre empresarios, actitud individualista, poca permanencia en proyectos de largo plazo conjuntos, divergencia de intereses y estrategias de negocio, además del incremento de los costos de control (Morales, Sanabria \& Arias, 2009; Sanín \& Sierra, 2005). Lo anterior resultante de un clima de competencia basado en la simetría de las empresas y la ausencia de productos diferenciados; esto se reafirma, en que el $71.4 \%$ de empresas aseguraron no haber realizado algún tipo de alianza ya sea con competidores o con entidades de apoyo. Adicionalmente, se observa que las asociaciones del sector aún no han logrado sinergias para trabajar de manera coordinada, lo cual hace que el proceso de generación de redes eficientes sea más lento y complejo.

- Débil trabajo con universidades y centros de formación: Medido en términos de proyectos conjuntos como aglomeración, pues los convenios que se realizan con instituciones educativas, se dan de manera individual para cada empresa y no en conjunto como concentración industrial (Morales, Sanabria \& Arias, 2009).

- Débil relación con centros de investigación y centros de desarrollo tecnológico: Se reconoce que los centros de investigación y desarrollo, aún no se consolidan como fuentes de conocimiento claves para las empresas de la aglomeración, dado el bajo nivel de credibilidad y la disposición para trabajar conjuntamente en proyectos reales de investigación, ya sea en producto, proceso u organización. Adicionalmente, la mayoría de empresarios a pesar de ser consientes de que el trabajo conjunto es importante, no se refleja esto en sus acciones, mostrando en algunos casos la resistencia a la implementación de nueva tecnología, en la que además influye los altos costos financieros que puede conllevar dicho proceso.

\subsubsection{Actividades de innovación}

Se identifica la necesidad de que las empresas realicen estudios más elaborados que se sustenten en procesos de investigación formales, con el fin de lograr captar información que aporte en mayor medida, para desarrollar conocimientos específicos y lograr innovaciones efectivas, pues se observa que solo el $28.6 \%$ de las empresas encuestadas, tienen personal dedicado a actividades de investigación y desarrollo. Adicional a lo anterior, son actividades que se enfocan al desarrollo del producto en diseño y normalmente están a cargo de una sola persona o un grupo reducido dentro de la empresa.

Con base en las respuestas de las empresas más representativas de la aglomeración, que fueron las que diligenciaron la encuesta, en relación con las actividades de innovación el $85.37 \%$ de los empresarios manifiesta haber realizado algún tipo de innovación ${ }^{22}$, de estas la mayoría identifican haber generado innovación de producto, seguida de la innovación organizacional y en el proceso (Ilustración 4), la innovación en mercadotecnia no se menciona. $\mathrm{Al}$ indagar por el origen de la innovación la mayoría de las empresas encuestadas dicen haber realizado el desarrollo internamente (Ilustración 5), adicionalmente el alcance de las innovaciones son en su mayoría de tipo local, seguido del nacional e internacional (empresas que exportan) (Ilustración 6). Así mismo se identifica que el grado de innovación para el $80 \%$ de las empresas que dicen haber realizado algún tipo de innovación es de tipo incremental.

22 Se toma como referente los tipos de innovación establecidas en el Manual de Oslo. 


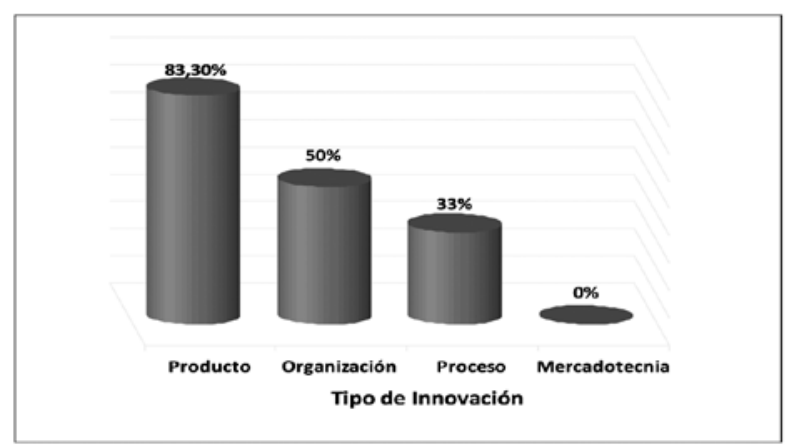

Ilustración 4. Tipos de innovación realizada ${ }^{19}$

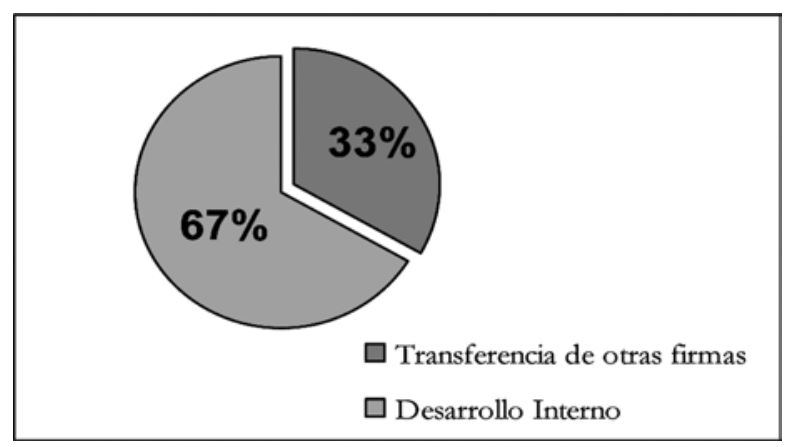

Ilustración 5. Origen de la innovación ${ }^{20}$

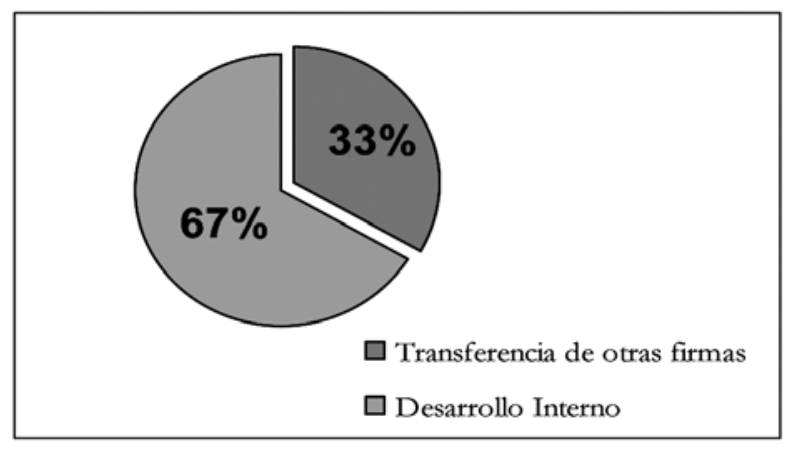

Ilustración 6. Alcance de innovación ${ }^{21}$

Tanto las asociaciones del sector como los empresarios, identificaron que las principales razones por la cuales no se realizan más procesos que conlleven a generar innovaciones, son los altos costos que se generan, seguido de la carencia de personal capacitado, la falta de soporte de las entidades de apoyo y en último lugar, por factores normativos y o legales, que no se consideran claros. De otra parte, también se pudo encontrar consenso en que las innovaciones identificadas no se consideran sostenibles en el tiempo, debido a que solo son mejoras del producto o proceso que rápidamente son copiadas. Sin embargo, quienes manifestaron haber realizado innovaciones efectivas, expresan que el proceso ha tenido un efecto positivo en la organización, principalmente asociado con un mejor posicionamiento frente a los competidores y un incremento en el nivel de ventas.

Los datos presentados sugieren que las organizaciones más destacadas de la aglomeración muestran un alto interés por lograr realizar innovaciones efectivas, dado el creciente nivel de competencia local, nacional e internacional; lo cual incentiva procesos de diferenciación ya sea en costos o diseño. Sin embargo, es claro que la capacidad de absorción de conocimiento es aun débil, pues son empresas que en su mayoría aún no tiene lineamientos claros en el fortalecimiento de su capital humano, por medio de programas que incentiven el desarrollo de conocimiento clave.

\subsection{Factores determinantes de la competitividad en la aglomeración del Barrio Restrepo de Bogotá D.C.}

La competitividad de la aglomeración estudiada se analizó con base en los determinantes del modelo del diamante de Michael Porter, encontrándose que existen diferencias significativas entre las condiciones halladas en la aglomeración objeto de estudio y aquellas evidenciadas por Porter, en su estudio sobre los sectores considerados de clase mundial en países industrializados. A continuación se hace una breve descripción del estado de cada uno de los determinantes, haciendo un paralelo con lo que ocurre en los países industrializados:

\footnotetext{
Elaboración propia.

20 Elaboración propia.

21 Elaboración propia.
} 
Condiciones de los factores: con relación a este determinante, es importante resaltar que la competitividad de los países industrializados está basada en factores creados, especializados y avanzados, como la tecnología, los recursos humanos especializados y la existencia de infraestructura de punta que soporte los procesos productivos de las organizaciones.

En la aglomeración estudiada se evidenciaron algunas debilidades:

Insumos y materias primas: La aglomeración enfrenta dificultades asociadas a la baja calidad del cuero debido a procesos inadecuados desde la cría misma del ganado; de igual forma, no existen plantas tecnológicamente aptas para la realización del proceso de curtición (Sanín \& Sierra, 2005; Departamento Nacional de Planeación, 2007), razón por la cual, algunos fabricantes de artículos de gama alta, recurren a la importación del cuero, lo cual conlleva a mayores costos; teniendo en cuenta que las pieles suelen ser exportadas a países como Italia a bajos precios, en donde se procesan para posteriormente ser traídas de regreso al país vía importaciones, para ser convertidas en producto final. Las importaciones de cueros y sintéticos provienen principalmente de Chile, Italia y Argentina. Otra dificultad que se evidencia en la aglomeración es la inexistencia de empresas enfocadas en la fabricación de maquinaría para la industria, la cual es importada de países como China y Alemania y es distribuida por un número muy reducido de empresas.

Recursos humanos: Si bien en la parte administrativa de las empresas, ya existe una buena participación de personal con nivel universitario (Departamento Nacional de Planeación y Fundación Corona, 1998) y con postgrado (Ilustración 3), aún se requiere concentrar esfuerzos en la formación del recurso humano con el fin de mejorar la capacidad de gestión de los empresarios y los niveles de innovación (Departamento Nacional de Planeación y Fundación Corona, 1998; Morales, Sanabria \& Arias, 2009).

Tecnología: Hay escasa incorporación de desarrollo tecnológico, encontrándose que las diferentes actividades que deben ejecutarse para la fabri- cación de los productos, en su mayoría se realizan de manera artesanal e implican la utilización de herramientas de baja tecnología, razón por la cual es considerado un sector intensivo en mano de obra (Departamento Nacional de Planeación y Fundación Corona, 1998; Sanín \& Sierra, 2005). Lo anterior explica la inexistencia de barreras a la entrada de nuevas empresas a la aglomeración, dado que no se requiere de una gran inversión en capital, conocimiento y tecnología (Morales, Sanabria \& Arias, 2009). De igual forma además de no contar con estructuras organizacionales bien definidas, no han incorporado sistemas computarizados para el registro y control de sus operaciones, presentándose problemas por ejemplo en el costeo de los bienes producidos.

Capital: Las empresas tienen débiles estructuras financieras debido a su reducido tamaño.

Infraestructura: En lo que concierne al acceso a servicios públicos como energía y agua e infraestructura vial, los empresarios manifestaron que es adecuado. En lo que atañe a medios de transporte las empresas cuentan con una gran ventaja y es estar ubicadas en la capital del país contando con un fácil acceso a un aeropuerto internacional y la disposición diferentes empresas de carga, tanto terrestre como aérea, para trasladar sus productos a cualquier parte del mundo.

De acuerdo con la visión global que sobre la aglomeración expresaron las asociaciones y de conformidad con un estudio realizado por el Departamento Nacional de Planeación y la Fundación Corona en el año 1998 y las encuestas realizadas en este estudio, se puede decir que la operación de la aglomeración está sustentada en recurso humano con baja formación - principalmente en el área operativa -, escasa incorporación de tecnología y baja inversión, lo cual incide en los bajos niveles de innovación y diferenciación del producto.

Condiciones de la demanda: la demanda en los países industrializados se caracteriza por ser exigente y jalonar los procesos de innovación en la industria, por el contrario en la aglomeración estudiada se encontró que la producción está dirigida 
principalmente a calzado de tipo popular, esto es de gama baja y media, en donde la demanda es poco exigente, respecto a la calidad y la diferenciación del producto (Sanabria \& Morales, 2009). Lo anterior se evidencia en el escaso uso de laboratorios de evaluación de materiales o mecanismos físico-técnicos confiables para evaluar la calidad del calzado, así por ejemplo laboratorios como los de CEINNOVA, son usados de manera esporádica, cuando se trata de validar la calidad de pedidos oficiales como los dirigidos a las fuerzas armadas (Departamento Nacional de Planeación y Fundación Corona, 1998).

Sectores afines y de apoyo: la competitividad de los sectores considerados de clase mundial está sustentada en la cercanía con proveedores internacionalmente competitivos, trabajo conjunto con universidades, centros de investigación y entidades financieras.

Como se evidenció anteriormente, en este aspecto, la aglomeración enfrenta dificultades, dado que no cuenta con proveedores de cuero y de maquinaria competitivos, motivo por el cual algunos empresarios tienen que recurrir a los mercados internacionales para adquirir estos bienes. Adicionalmente, las relaciones con los fabricantes de insumos son casi inexistentes, teniendo en cuenta que la mayoría de las veces los empresarios no tienen contacto con los mismos, ya que estos adquieren los insumos a través de las peleterías. Lo anterior, teniendo en cuenta que los grandes fabricantes de insumos, ven con desconfianza al microempresario por su bajo respaldo financiero y el bajo volumen de compra, razón por la cual no les interesa establecer relaciones directas con ellos (Departamento Nacional de Planeación y Fundación Corona, 1998).

Por otra parte, las relaciones universidad-empresaEstado son débiles (Sanabria \& Morales, 2009), lo cual se ve reflejado en los bajos niveles de incorporación de profesionales de carreras como diseño industrial, diseño de modas, ingeniería y administración de empresas en las organizaciones, así como en la inexistencia de políticas públicas que incentiven el desarrollo de la aglomeración, la financiación de proyectos específicos de beneficio para el sector y lo relacionado con la disminución de los altos índices de informalidad registrados en el sector.

Finalmente, si bien la aglomeración dispone en sus proximidades con tres asociaciones relacionadas con la industria - ANSECALZ, ACICAM y CEINNOVA - la primera de ellas ubicada en la aglomeración, son pocos los empresarios miembros y algunos aunque se encuentran afiliados, no hacen uso de los servicios ofrecidos por las mismas. Lo anterior refleja la escasa credibilidad de este tipo de instituciones y la baja disposición de los empresarios a cooperar.

Estrategia, estructura y rivalidad de las empresas: como referente en este aspecto, se tiene que la competitividad de los sectores considerados de clase mundial se basa en la diferenciación de productos, la innovación y el avance tecnológico.

En lo que respecta a la aglomeración, se encontró que la competencia en la misma está basada en precios, lo cual induce a bajos niveles de utilidad (Departamento Nacional de Planeación y Fundación Corona, 1998; Sanabria \& Morales, 2009) y al cierre de empresas, debido a la existencia de competencia predatoria. Todo ello, influenciado por la presencia de una cultura de la imitación de producto y la falta de procesos de investigación y desarrollo que generen innovaciones.

No hay asociatividad ni horizontal ni vertical entre los empresarios que conforman la aglomeración, lo cual incide en la inexistencia de una marca común que represente la industria en los mercados extranjeros y en la suma de esfuerzos para fortalecer las débiles estructuras financieras y productivas de las organizaciones.

Adicionalmente es necesario mencionar que la industria enfrenta una fuerte competencia de productos provenientes principalmente de China, estimulada por la revaluación de la moneda (Cámara de Comercio de Bogotá, 2005; Sanabria \& Morales, 2009).

El gobierno: el gobierno en los países industrializados juega un rol parcial dado que existe un sec- 
tor privado completamente consolidado, fuerte y competitivo. Sin embargo, en países en desarrollo, particularmente en la aglomeración estudiada, se considera que el gobierno debe jugar un papel más activo tanto en la creación de factores especializados y avanzados, como en el fomento de la industria, a través de políticas públicas que incentiven la cooperación y la formalización de las empresas.

La casualidad: la existencia de un sector privado consolidado y competitivo en los países desarrollados hace que variables como las tasas de cambio, la tasa impositiva, y las políticas presupuestarias tengan bajo impacto, dado que ante cualquier fluctuación sus fuertes estructuras financieras pueden implementar medidas contingentes para contrarrestarlas. Sin embargo, para el caso de la aglomeración del Barrio Restrepo, se evidenció que estas variables juegan un rol importante; por ejemplo las fluctuaciones en las tasas de cambio han incidido en el hecho de que algunas empresas tengan que cerrar por el incremento en el costo de los bienes importados, que no puede ser compensado a través de incrementos en los precios o aumento en la escala de producción, debido a la débil estructura financiera y productiva de las empresas consideradas individualmente (Sanín \& Sierra, 2005). De igual forma, la existencia de problemas diplomáticos con algunos gobiernos, ha incidido tanto en el acceso a materias primas provenientes de los mismos, como en el mercado del producto generado por la aglomeración.

Del análisis anterior, se puede concluir que la competitividad de la aglomeración es baja, con respecto a las condiciones encontradas en otros sectores de la actividad económica en países industrializados. Es importante aclarar que aunque existen algunas empresas competitivas individualmente, como cluster aún falta superar algunas dificultades, principalmente asociadas a la cooperación tanto vertical como horizontal ya que esta es la base fundamental de los mismos y la que permite que se generen beneficios al agregado de empresas.

Lo evidenciado permite además, clasificar la aglomeración estudiada dentro de la categoría de clusters de micros y pequeñas empresas sobrevivientes de- terminada por Altenburg (2001) teniendo en cuenta que el autor los caracteriza como concernientes principalmente a sectores de bajo contenido tecnológico y reducida inversión, en donde la competencia está basada en precios inhibiendo la disposición de los empresarios a cooperar, profundizada por factores como capacidad de gestión poco desarrollada, inestabilidad social, volatilidad de las empresas y falta de mecanismos legales para la solución de conflictos, adicionalmente los productos en general son de baja calidad y no diferenciados.

La tabla 5 presenta un análisis DOFA de la aglomeración que consolida lo mencionado anteriormente y que comparte algunos de los hallazgos evidenciados por Sanín \& Sierra (2005) y Departamento Nacional de Planeación (2007) en estudios realizados en el sector.

\section{4. ¿Es la aglomeración empresarial estudiada un cluster?}

Finalmente, una vez caracterizadas las dinámicas de acumulación de conocimiento, innovación y competitividad en la aglomeración del Barrio Restrepo, es importante determinar si esta concentración puede ser catalogada como "Cluster" o es simplemente una aglomeración de empresas dispuesta de manera aleatoria y desarticulada. En este sentido se analizará a la luz del concepto de cluster acuñado por Porter (2003).

Retomando a Porter (2003) un cluster puede ser definido de la siguiente manera:

"Un cúmulo es un grupo geográficamente denso de empresas e instituciones conexas, pertenecientes a un campo concreto, unidas por rasgos comunes y complementarias entre sí. Por su dimensión geográfica, un cúmulo puede ser urbano, regional, nacional o incluso supranacional. Los cúmulos adoptan varias formas, dependiendo de su profundidad y complejidad, pero la mayoría de ellos comprenden empresas de productos o servicios finales, proveedores de materiales, componentes, maquinaria $y$ servicios especializados, instituciones 
Tabla 5. Análisis DOFA de la aglomeración²2

\begin{tabular}{|c|c|}
\hline DEBILIDADES & OPORTUNIDADES \\
\hline $\begin{array}{l}\text { Baja formación académica del recurso humano. } \\
\text { Alta rotación de personal. } \\
\text { Escasa incorporación del elemento tecnológico en el proceso } \\
\text { productivo. } \\
\text { Débiles relaciones universidad - empresa - Estado. } \\
\text { Ausencia de cooperación vertical y horizontal. } \\
\text { Débil estructura financiera y productiva. } \\
\text { Ausencia de algunos eslabones de la cadena productiva. } \\
\text { Baja calidad de los insumos. } \\
\text { Bajos niveles de innovación y diferenciación del producto. } \\
\text { Falta de una marca común que represente al producto gene- } \\
\text { rado por la aglomeración y que permita hacer extensivas las } \\
\text { políticas de marketing. } \\
\text { Falta de especialización y división del trabajo. } \\
\text { Altos niveles de informalidad empresarial. } \\
\text { Débil gestión del conocimiento dentro de las empresas. } \\
\text { Sistema de conocimiento débil y poco estructurado. }\end{array}$ & $\begin{array}{l}\text { Experiencia de las empresas que han incursionado en los mer- } \\
\text { cados internacionales, con el fin de hacer transferencia de co- } \\
\text { nocimiento. } \\
\text { Posibles tratados de libre comercio en donde al competir con } \\
\text { calidad y diferenciación la industria puede desarrollar ventajas } \\
\text { competitivas. } \\
\text { Interés por parte de empresarios de diferentes países de Amé- } \\
\text { rica Latina y Europa quienes han manifestado querer hacer ne- } \\
\text { gocios con empresarios colombianos. } \\
\text { Conocimientos y experiencia de otras aglomeraciones de cal- } \\
\text { zado en el país el cual puede ser transferido con la ayuda de las } \\
\text { asociaciones del sector. } \\
\text { Realización y participación de los empresarios en ferias impor- } \\
\text { tantes de la industria. }\end{array}$ \\
\hline FORTALEZAS & AMENAZAS \\
\hline $\begin{array}{l}\text { Recurso humano con alta experiencia y conocimiento del sec- } \\
\text { tor. } \\
\text { Existencia de asociaciones cuyo propósito es el apoyo a los } \\
\text { empresarios, y que a su vez tienen cercanía a la aglomeración. } \\
\text { Existencia de una gran masa de empresas. } \\
\text { Larga tradición empresarial. } \\
\text { Presencia de empresas competitivas que tienen potencial para } \\
\text { transferir conocimiento. }\end{array}$ & $\begin{array}{l}\text { Importación de calzado con mayor calidad o a bajo precio. } \\
\text { Contrabando del producto } \\
\text { Acuerdos comerciales internacionales exigentes en términos de } \\
\text { calidad y diseño. } \\
\text { Competencia por mano de obra con otros sectores económi- } \\
\text { cos debido a su ubicación, en una ciudad donde confluyen di- } \\
\text { ferentes actividades. } \\
\text { Reformas fiscales y laborales que desincentivan a los empre- } \\
\text { sarios. }\end{array}$ \\
\hline
\end{tabular}

financieras y empresas de sectores afines. En los cúmulos también suelen integrarse empresas que constituyen eslabones posteriores de la cadena (es decir, canales de distribución o clientes); fabricantes de productos complementarios; proveedores de infraestructura; las instituciones públicas y privadas que facilitan formación, información, investigación y apoyo técnico especializado (universidades, grupos de reflexión, entidades de formación profesional) y los institutos de normalización" (Porter, 2003, 205).
En relación con la anterior definición, Porter (2003) propone la siguiente metodología para identificar los elementos constitutivos de un cluster y que permiten catalogarlo como tal:

A. Identificar una gran empresa o concentración de empresas similares y observar los niveles superiores e inferiores de la cadena vertical de empresas e instituciones: con relación a ello, la aglomeración del Barrio Restrepo es una concentración de empresas similares, particularmente micros y pequeñas empresas, en la cual se pueden encontrar los diferentes eslabones de la cadena vertical, como son proveedores

22 Elaboración propia. 
de insumos, fabricantes, canales de distribución y clientes. Los únicos eslabones que no se encuentran representados en esta ubicación son los relacionados con las curtiembres y la fabricación de maquinaria para la industria, la cual es importada de países como Alemania y China.

B. Observar horizontalmente para identificar sectores que pasan por canales similares o que producen bienes o servicios similares. Las cadenas horizontales adicionales de sectores, pueden identificarse en función del empleo de tecnologías o materiales especializados similares, en función de otros nexos de relación correspondientes a la oferta: en el nivel horizontal en la aglomeración mencionada, se pueden encontrar empresas dedicadas a la fabricación de diferentes tipos de calzado - dama, caballero, niño - así como empresas que se dedican a la marroquinería y prendas de vestir en cuero.

C. Determinar qué instituciones le proporcionan los conocimientos, tecnologías, información, capital $e$ infraestructuras especializadas y en que organismos colectivos están integrados sus miembros: en lo referente a instituciones que proporcionan conocimiento y apoyo a la aglomeración se pueden identificar tres asociaciones las cuales son: Asociación Nacional del Sector del Calzado, el Cuero y Afines (ANSECALZ \& AFINES), la Asociación Colombiana de Industriales del Calzado, el Cuero y sus Manufacturas (ACICAM), Seccional Bogotá y Cundinamarca, la cual cuenta con sedes en diferentes partes del país y el Centro Tecnológico para la Industria del Calzado, Cuero y Afines (CEINNOVA). De estas tres asociaciones sólo la primera tiene su sede en el Barrio Restrepo, las otras se encuentran ubicadas en diferentes partes de la ciudad.

De igual forma, se pueden encontrar diferentes instituciones educativas que sin estar localizadas en dicha ubicación realizan o podrían realizar aportes de conocimiento a la aglomeración como son las universidades y centros de forma- ción técnica y tecnológica como el SENA. Sin embargo, un miembro de una de las asociaciones entrevistadas, manifestó que los servicios proporcionados por algunas de estas entidades, no están alineadas con las necesidades del sector privado, dado que imparten formación con base en procesos anticuados, que ya no tiene aplicabilidad práctica en la industria.

Al respecto Porter (2003) menciona que si bien algunos cúmulos giran en torno a las universidades, otros no tienen conexiones importantes con las mismas, como sucede en este caso en donde el aporte de conocimiento es demasiado limitado dado que la mayor parte de él es tácito y se transmite a través de la experiencia y el contacto cara a cara. Adicionalmente, la débil estructura financiera de la mayoría de las empresas, no les permite acceder a los servicios de personal calificado y en muchas ocasiones, esto no se considera necesario, por lo tanto se hace poco uso de conocimiento científico y los procesos de innovación son escasos.

En lo que respecta a las instituciones financieras, en dicha ubicación se encuentran sucursales de un gran número de ellas, debido a la gran cantidad de transacciones que se originan en el comercio y la industria de la zona. Sin embargo, no se encontró que hubiese entidades especializadas en prestar servicios financieros a la industria del calzado, cuero y afines, aunque no se descarta que informalmente existan bajo modalidades como el préstamo gota a gota, entre otras.

D. Establecer los órganos de la Administración y otros cuerpos normativos que influyen significativamente en los componentes del cúmulo: aunque no hay entes administrativos especializados que ejerzan una influencia directa en la aglomeración, se encuentran entidades como el Ministerio de Industria y Comercio, las Cámaras de Comercio, las alcaldías, entidades de fomento a la industria en general, quienes con su actuación impactan la industria a través de su normatividad y supervisión. 
Siguiendo la metodología propuesta por Porter (2003) y una vez identificados los elementos de la definición, se podría afirmar que la aglomeración objeto de estudio sí es un cluster. Sin embargo, es necesario profundizar un poco más en los aportes del mencionado autor con el fin de fortalecer dicha afirmación o por el contrario refutarla.

Retornando a la definición acuñada por Porter (2003) y trayendo a colación una de las críticas antes mencionadas, relacionada con el hecho de que el mencionado autor, no define de manera específica el tipo de relaciones que se deben gestar entre los actores que componen la aglomeración (Martin \& Sunley, 2003), se encuentra que en apartados adicionales Porter (2003) hace algunas referencias a este respecto. Por ejemplo, arguye que las fronteras de un cúmulo deben abarcar a todas las empresas, sectores y entidades que tengan entre sí relaciones sólidas, ya sean verticales, horizontales o institucionales; aquellas cuyas relaciones sean débiles o inexistentes pueden quedar al margen sin ningún problema.

Adicionalmente, Porter (2003) menciona que en los clusters las empresas compiten pero también cooperan, resaltando la importancia de las relaciones entre los miembros del cluster, la complementariedad y la influencia indirecta que se genera en cuestión de tecnología, conocimientos prácticos, información, marketing y necesidades de los clientes, lo cual contribuye a la creación de ventajas competitivas. De igual forma, considera que estas conexiones son esenciales para la competencia, la productividad, y sobre todo, para la orientación y el ritmo de formación de nuevas empresas y la innovación. El cúmulo constituye un foro constructivo y eficaz para el diálogo entre empresas afines y sus proveedores, las autoridades y otras instituciones.

Aunque estos elementos son importantes en la constitución de un cluster, Porter (2003) también reconoce que los cluster pueden estar tanto en grandes sectores como en pequeños y que pueden tener diferentes dimensiones y grados de desarrollo, afirmando que los clusters en economías industrializadas suelen estar más desarrollados que los clusters en economías en vías de desarrollo.
De lo anterior se puede afirmar que si bien las empresas de la aglomeración estudiada están desarticuladas y las relaciones que se gestan entre ellas no trascienden los límites del mero intercambio de bienes y servicios, ésta se puede considerar un cluster potencial, en etapa de desarrollo, dado que a pesar de que existen empresas competitivas individualmente, no hay interacción entre ellas (Buitelaar, 2000). Es importante anotar que la falta de articulación entre las empresas de la aglomeración estudiada, se origina en factores culturales como la falta de confianza y de compromiso entre empresarios, el egoísmo, el oportunismo, entre otras cosas, en el que solo un cambio a nivel de valores puede contribuir a mejorar la situación de la aglomeración.

\section{Conclusiones y recomendaciones}

El estudio de las aglomeraciones empresariales desde diferentes disciplinas no es reciente; sin embargo, en las dos últimas décadas ha tomado importancia, en razón a que las características de la economía actual, favorecen y promueven este tipo de estructuras organizacionales, con el argumento de que dichas estructuras, propician la innovación y por tanto permiten ser más competitivos. La evidencia empírica muestra que ciertos países industrializados, logran desarrollar procesos dinámicos de innovación, a partir de la formación e incentivo de aglomeraciones industriales, clusters o distritos industriales. Pero, en economías emergentes como las de América Latina, aunque existen algunas políticas de apoyo gubernamental para la formación y desarrollo de aglomeraciones empresariales tipo cluster, estas todavía no logran el impacto deseado y los procesos de innovación dentro de estas agrupaciones siguen siendo escasos.

La generación, acumulación y transferencia de conocimiento, dentro de las aglomeraciones empresariales, se ha convertido en un factor estratégico, que permite generar ventajas competitivas reales, a partir del desbordamiento de conocimiento y su utilización para la realización de innovaciones efectivas. Los resultados de la revisión de literatura especializada, muestran que aunque las sinergias que producen las aglomeraciones o clusters, son de gran 
beneficio para las empresas localizadas y en general para las industrias, este fenómeno no se da por igual en todos los países. Así, se observa que gran parte de los países desarrollados, han logrado generar un dinámica de innovación y gestión de conocimiento efectiva, mientras que en países como los de Latinoamérica, este proceso ha sido lento, debido especialmente al afán de los gobiernos, por incorporar este modelo de desarrollo regional, sin haber desarrollado antes las estructuras físicas y sociales que posibilitarían su efectividad.

Para la comprensión de la competitividad, existen diversos modelos, pero uno de los más utilizados para el estudio de las aglomeraciones empresariales tipo cluster, es el Modelo del Diamante de Michael Porter. Sin embargo, es claro que al aplicarlo a un entorno diferente a aquel que le dio origen, presenta limitantes, por lo que se debe tener cuidado en su aplicación, cuestionar o evaluar su pertinencia, para la comprensión de los factores que intervienen o generan competitividad en aglomeraciones empresariales de países en desarrollo como Colombia. Lo anterior debido a que existen serias debilidades en el estado de los componentes del diamante y se puede llegar a conclusiones herradas.

Los resultados de la investigación muestran que la simple aglomeración de empresas en una localización determinada no garantiza la existencia de externalidades dinámicas que beneficien al conjunto de empresas ubicadas en el área, dado que éstas, más que de la proximidad, dependen de factores de tipo cultural, de la idiosincrasia de los individuos y de las condiciones sociales y económicas presentes en un momento determinado, las cuales son resultado de la evolución histórica de la sociedad. En este sentido, aún cuando la aglomeración de empresas del Barrio Restrepo tiene un legado de más de 50 años, aún existen barreras para generar procesos de integración tanto vertical como horizontal y para establecer vínculos con entidades conexas y de apoyo como las asociaciones de la industria y las universidades, que les permita generar dinámicas de innovación. Lo anterior dada la presencia de factores asociados especialmente a la cultura de los empresarios, a las características propias de la actividad económica y a condiciones políticas, sociales, económicas e institucionales del entorno. Por tanto la aglomeración del Barrio Restrepo es catalogada como un cluster en etapa de desarrollo, al cual le falta emprender procesos de cooperación para lograr constituirse en un cluster maduro y competitivo.

Así mismo, aunque se reconoce que la cooperación en un ambiente de competencia promueve procesos de creación y absorción de conocimiento, que se deben convertir en base para la creación de innovaciones efectivas, para las empresas pertenecientes a la aglomeración; aún en la aglomeración estudiada, se deben generar procesos efectivos de gestión de conocimiento dentro de cada empresa, así como programas de fortalecimiento y conformación de redes de conocimiento y producción, encaminadas a desarrollar relaciones con las universidades, centros de investigación y el Estado, que promuevan la competitividad, a partir de la generación y transferencia del conocimiento, que repercuta en los procesos de innovación, pues actualmente dentro de la aglomeración, no existe un ambiente propicio para la generación de innovaciones efectivas que trasciendan a toda la aglomeración.

Teniendo en cuenta las características del sector y la baja competitividad que la industria del calzado y afines puede alcanzar en la fabricación de sus productos, dadas las bajas economías de escala y la intensa competencia de productos importados, se debe profundizar en conceptos como la moda, el diseño, la calidad, la diferenciación y el posicionamiento de marca, para lo cual se requiere entre otras cosas, la transformación productiva de las empresas y la formación de capacidades en innovación, que es en donde se observa una mayor debilidad. En este sentido, se considera que las empresas que participaron en el estudio, pueden convertirse en punto de partida para iniciar procesos encaminados al fortalecimiento del cluster, ya que presentan algunas características que les permiten consolidarse como las más representativas de la aglomeración y pueden servir como guía para otras empresas que quieran a través de la dinámica de cluster, desarrollar su competitividad.

Finalmente, se considera de especial importancia el papel que puedan jugar la asociaciones, en el proceso de consolidación del cluster, dada su cercanía 
al entramado empresarial y teniendo en cuenta que son conocedores de las dificultades que enfrenta la aglomeración. De igual forma es estratégico fortalecer las relaciones entre universidad, empresa y Estado con el fin de mejorar los procesos de innovación y acumulación de conocimiento, factores considerados clave de la competitividad en el actual contexto económico.

\section{Referencias}

Alburquerque, F. (2006). Cluster, territorio y desarrollo empresarial: diferentes modelos de organización productiva. Cuarto taller de la red de proyectos de integración productiva BID / FOMIN. Julio, Costa Rica.

Altenburg, T. (2001). La promoción de clusters industriales en América Latina: Experiencias y Estrategias. Instituto Alemán de Desarrollo._Buenos Aires: Focopyme.

Arias, M \& Morales, M. (2009). Barreras para la transferencia de conocimiento y la innovación en una aglomeración industrial. Encuentro de investigadores en prospectiva, innovación y gestión del conocimiento. Universidad del Valle. Octubre 22 y 23, Cali, Colombia,

Audretsch, D. \& Feldman, M. (1996). "R\&D Spillovers and the geography innovation and production". En: The journal economic review, 86 (3): 630-640.

Becerra, F. y Naranjo, J. (2008). "La innovación tecnológica en el contexto de los clusters regionales". En: Cuadernos de Administración 21 (37): 133-159.

Bell, M \& Albu, M. (1999). "Knowledge Systems and Technological Dynamism in Industrial Clusters in Developing Countries". En: World Development. 27 (9): 1715-1734.

Brenner, T \& Greif, S. (2006). "The dependence of innovativeness on the local firm population: an empirical study of German patents". En: Industry and Innovation, 13(1): 21-39.

Buitelaar, R. (2000). Cómo crear competitividad colectiva. CEPAL, Santiago de Chile.

Cámara de Comercio de Bogotá (2005). Caracterización de las cadenas productivas de manufactura y servicios en Bogotá y Cundinamarca.

Cámara de Comercio de Bogotá (2007). "Perfil económico y empresarial. Localidad Antonio Nariño". Disponible en: http//: www.ccb.org.co

Capello, R \& Faggian, A. (2005). "Collective learning and relational capital in Local innovation processes". En: Regional Studies, 39(1): 75-87.

Castro, J, Rocca, L \& Ibarra, A. (2008). "Transferencia de conocimiento en las empresas de la comunidad autónoma del país vasco: capacidad de absorción y espacios de interacción de conocimiento". En: ARBOR Ciencia, Pensamiento y Cultura. CLXXXIV (732): $653-675$

Céspedes, J \& Martínez, J. (2006). "Generación y difusión de la innovación en distritos industriales". En: Revista MADRI+D 36, España. Tomado de: http://www.madrimasd.org/revista/ revista36/tribuna/tribuna3.asp.

CONPES 3527, (2008). Documento CONPES 3527: Política Nacional de Competitividad y Productividad.
Corrales, S. (2007). "Importancia del Cluster en el Desarrollo Regional Actual”. En: Frontera Norte, 19. (037): 173 - 201.

Cowan, R, Jonard, N \& Özman, M. (2004). "Knowledge dynamics in a network industry". En: Techological Forecasting \& Social Change. 71: 469-484. Disponible en: http://www.sciencedirect.com/science? ob=Mlmg\& imagekey=B6V7148XD9K9-1.

Chaminade, C. (1999). "Innovation processes and knowledge flows in the information and communications technologies cluster in Spain". En: Boosting Innovation: the Cluster Approach: 219 239. Disponible en http://www.clusterbg.net/content/library/ EN/Boosting Inovations Cluster Approach.pdf

Dahlman, C. (2007). "The Challenger of the knowledge economy for Latin America". En: Journal. Globalization, competitiveness \& governability. Georgetown University. 1 (1):18-46.

Departamento Nacional de Planeación y Fundación Corona (1998). Microempresa y Competitividad, Cuero. CEINNOVA - Centro de Innovación y Servicios para la Industria del Calzado. Impresión Panamericana.

Departamento Nacional de Planeación (2007). Agenda interna para la productividad y la competitividad.

Diccionario de la Real Academia Española, (2010). Disponible en http://www.rae.es

Fernández, V. \& Vigil, J. (2007). "Clusters y desarrollo territorial: Revisión teórica y desafíos metodológicos para América Latina". En: Economía, Sociedad y Territorio. VI (24): 859 -912.

Gilbert, B, Mc Dougall, P \& Audretsch, D. (2008). "Cluster, knowledge spillovers and new venture performand: an emphirical examination". En: Journal of businness venturing 23: $404-422$.

Hoover, E. (1943). Economía Geográfica. México; Editorial Fondo de Cultura Económica (Fce)

Jacobs, J. (1969). The Economy of Cities. New York; Vintage.

Ketels, C. (2003). The devolompent of the cluster concept: present experiencies and further developments. Prepared for NRW conference on clusters, 5 Dec, Duisburg, Germany.

Krugman, P. (1953). Desarrollo, Geografía y Teoría Económica. Barcelona : Antoni Bosch editor.

Maldonado, N. (2004). "Innovación tecnología como factor de aglomeración espacial en las regiones colombianas". En: Cuadernos de economía XXIII (41): 71- 107.

Malmberg, A, Solvell, O, \& Zander, I. (1996). "Spatial clustering, local accumulation of knowledge and firm competitiveness". En: Geografiska Annaler. Series B, Human Geography, 78 (2): 85-97

Malaver, F. \& Vargas, M. (2004). "Los procesos de innovación en la industria colombiana: Resultados de un estudio de casos". En: Cuadernos de Administración, Pontificia Universidad Javeriana, 17 (28): 9 - 42.

Marshall, A. (1890). Principios de Economía: un tratado de introducción. Madrid: Aguilar

Martin, R \& Sunley, P. (2003)."Deconstructing clusters: Chaotic concept or policy panacea?". En: Journal of Economic Geography, Oxford University Press, 3(1): 5-35.

Maskell, P \& Kebir, L. (2005). "What qualifies as a cluster theory?". En: Druid working paper No. 05-09.

Martínez, P. (2006). "El método de estudio de caso: estrategia metodológica de la investigación científica". Disponible en: http://ciruelo.uninorte.edu.co/pdf/pensamiento_gestion/20/5 El metodo_de estudio_de_caso.pdf 
Morales, M, Sanabria, S \& Arias, M. (2009). Perspectivas de la Acumulación de Conocimiento como Factor de Innovación en Aglomeraciones Industriales de Países Emergentes. XIII Seminario Latino-Iberoamericano de Gestión Tecnológica. Asociación Latino-lberoamericana de Gestión Tecnológica ALTEC. Cartagena de Indias, Colombia. Noviembre 25 al 27.

Nonaka, I \& Takeuchi H. (1999). La organización creadora de conocimiento: cómo las compañías japonesas crean la dinámica de la innovación. Editorial Oxford University Perss

Nooteboom, B. (2003). Inter-firm collaboration, learning and networks: An integrated approach. London: Routledge.

OCDE (1999). Boosting Innovation: the Cluster Approach. París: OCDE.

OCDE y EUROSTAT, (2006). Manual de Oslo: Guía para la recogida e interpretación de datos sobre innovación. Tercera Edición. París: Grupo Tragsa.

Parto, S. (2008). "Innovation and economic activity: an institutional analysis of the role of clusters in industrializing economies. En: Journal of economics issues. December, Association for Evolutionary Economics. 42 (4): 1005-1030.

Pietrobelli, C \& Rabellotti, R. (2005). Mejora de la Competitividad en Clusters y Cadenas Productivas en América Latina. El papel de las Políticas. Banco Interamericano de Desarrollo.

Porter, M. (1991). La Ventaja Competitiva de las Naciones. Vergara, Buenos Aires, Argentina

Porter, M. (2003). Ser Competitivos: nuevas aportaciones y conclusiones. Bilbao: Ediciones Deusto.

Rosenthal, S \& Strange, W. (2004). "Evidence on the Nature and Sources of Agglomeration Economies". Disponible en: http://www.rotman.utoronto.ca/ wstrange/RS Evidence\%20on\%20the\%20Nature\%20and\%20Sources\%20of\%20 Agglomeration\%20Economies\%20\%208-24-03.pdf.
Salinas, M. (2004). Reseña de "Croissance des villes et économie du savoir" de Alain Lapointe. En: Urban Public Economics Review, Universidad de Santiago de Compostela . 1 (002): 107-111.

Sanabria, S \& Morales M. (2009). Una aproximación al estudio de la competitividad de aglomeraciones industriales tipo cluster en América Latina. XIV Congreso Internacional de Contaduría, Administración e Informática. Universidad Nacional Autónoma de México. México D.F. Octubre 7,8 y 9.

Sanín, R \& Sierra, J. (2005). Proceso de desarrollo del cluster (una forma práctica) sobre la cadena productiva del sector calzado en cuero en Bogotá. Trabajo de Grado para optar por el Título de Administrador de Empresas, Universidad Militar Nueva Granada, Bogotá

Santos, J, Martínez, R \& Pajares, J. (2005). "Fenómenos de difusión de conocimiento y dimensión geográfica de la innovación, una aproximación multi- agente". En: IX Congreso de Ingeniería de Organización, Gijón. Disponible en: http:// io.us.es/cio2005/items/ponencias/121.pdf

Solvell, O, Lindqvist, G, \& Ketels, C. (2003). "The Cluster Initiative Greenbook". Disponible en: www.dpt.gov.tr/bgyu/...Cluster.../5.Cluster initiative greenbook.pdf

Vega, R. (2007). "Una crítica al desarrollo regional mediante clusters industriales forzados". En: Estudios Sociológicos XXV. (75):683- 707.

Vera, J \& Ganga, F. (2007). "Los clusters industriales: precisión conceptual y desarrollo teórico". En: Cuadernos de Administración 2. (33): 303-322.

Zozaya, V. (2006). "Las Redes y la Transferencia de Conocimiento". Boletín GC: Gestión Cultural. Redes culturales. 14: 3-9. Disponible en: http://www.gestioncultural.org/boletin/2006/ bgc14-VZozaya.pdf. 